Review

\title{
Microbiome engineering and plant biostimulants for sustainable crop improvement and mitigation of biotic and abiotic stresses
}

\author{
Received: 29 November 2021 / Accepted: 25 January 2022 \\ Published online: 05 February 2022 \\ (c) The Author(s) 2022 OPEN
}

Su-Ee Lau ${ }^{1,2} \cdot$ Wee Fei Aaron Teo ${ }^{1} \cdot$ Ee Yang Teoh ${ }^{1} \cdot$ Boon Chin $\operatorname{Tan}^{1}$ (I)

\begin{abstract}
Globally, despite the intense agricultural production, the output is expected to be limited by emerging infectious plant diseases and adverse impacts of climate change. The annual increase in agricultural output to sustain the human population at the expense of the environment has exacerbated the current climate conditions and threatened food security. The demand for sustainable agricultural practice is further augmented with the exclusion of synthetic fertilizers and pesticides. Therefore, the application of plant microbiome engineering and (natural) biostimulants has been at the forefront as an environment-friendly approach to enhance crop production and increase crop tolerance to adverse environmental conditions. In this article, we explore the application of microbiome engineering and plant biostimulants as a sustainable approach to mitigating biotic and abiotic stresses and improving nutrient use efficiency to promote plant growth and increase crop yield. The advancement/understanding in plant-biostimulant interaction relies on the current scientific research to elucidate the extent of benefits conferred by these biostimulants under adverse conditions.
\end{abstract}

Keywords Biostimulants $\cdot$ Biotechnology $\cdot$ Climate change $\cdot$ Crop improvement $\cdot$ Microbiome engineering $\cdot$ Sustainable food production

\section{Introduction}

Crop productivity will see a $60-100 \%$ increase by 2050 to meet the projected global population of 9.7 billion [1]. However, achieving this goal without damaging the agricultural system is challenging. The current agricultural sector and food production systems are threatened by various factors, including climate change, land degradation, water availability, and, more recently, a pandemic. For example, agricultural arable land has been continuously reduced [2] due to urban development and industrialization, while municipal and agricultural water demand is increasing, driven by population growth. Therefore, increasing crop productivity on existing agricultural land in a sustainable way is imperative. To achieve a better yield, farmers tend to apply chemical fertilizers. Nevertheless, overuse of chemical fertilizers in agro-ecosystem may damage soil health and the environment. Furthermore, the use of chemicals raises expectations for increased output or production costs, thus reducing farmers' income.

Climate change has become the most significant issue the world is currently facing. Climate change-induced losses to production have triggered public anxiety because they pose food security risks. The effects of climate change have been observed in several countries. In the US alone, the combined impact of drought and the increased temperature

$\triangle$ Boon Chin Tan, boonchin@um.edu.my $\mid{ }^{1}$ Centre for Research in Biotechnology for Agriculture, Universiti Malaya, 50603 Kuala Lumpur, Malaysia. ${ }^{2}$ Department of Cell and Molecular Biology, Faculty of Biotechnology and Biomolecular Sciences, Universiti Putra Malaysia, 43400 Serdang, Malaysia. 
has caused a total loss of $\$ 77.9$ billion for the past ten years (2010-2019) in agricultural production [3]. About 30\% of agricultural losses ( \$29 billion) reported in developing countries were associated with drought from 2005 to 2015 [4]. The disruption of food production systems is prevalent in developing countries, whose economies primarily rely on their agricultural output. For instance, about 29 million people in the Southern African Development Community countries were experienced food insecurity due to the El Niño-induced drought in 2016 that left many people in need of food aid.

Given that the current farmers' management practices are inadequate to meet global food demand and cope with the agricultural vulnerability due to climatic change, significant innovations are imperative to ensure sustainable crop production and food security. While many of us hope to see the world produce more foods with limited resources, the question is, will this be possible? Can we produce sufficient quality foods for the fast-growing human population in a sustainable way?

The yield of grain crops (e.g., rice, wheat, and maize), which provide $2 / 3$ of the intake of human and livestock calories, have already reached a "plateau" [5]. Although efforts have been made to increase crop yields by introducing mechanization, using improved crop varieties, and improving crop management practices [6], the rate of yield increment is insufficient for the growing population. For example, the crop breeding program is always limited by the very long crop duration [7]. Induced mutagenesis has also been used to develop new varieties with improved agronomic characteristics, such as increased stress tolerance potential and bio-fortification [8]. This approach is one of the most efficient tools in increasing the genetic variability for desired traits in various food crops. However, since the induced mutagenesis is random, many unwanted mutations may occur. Genetic engineering or genome editing approaches are undoubtedly an alternative to counter losses in crop yield caused by global climate change. However, their use is strictly restricted or not legally permitted in several countries [9].

With regard to plant protection, damages caused by pests and diseases have adversely affected crop productivity. Consequently, chemical pesticides have become vital as crop protection measures. Herbicides have accounted for about $45 \%$ of all pesticides used in agriculture [10]. The increasing use of pesticides has raised concerns about potentially harmful effects on natural ecosystems and human health. However, the apparent improvement in crop yield due to chemical pesticides has dissuaded farmers from abandoning the chemical pesticides regime [11, 12]. Despite its application benefits, the persistence of pesticide residues in soils has led to a "call for action" to reduce pesticide usage. Hence, finding sustainable methods to improve crop productivity and stress tolerance to environmental stress factors while reducing the use of pesticides is indispensable.

Do we have a solution to improve crop productivity sustainably? Of course, we do. With the advent of modern biotechnologies, it is now possible to tackle these complex problems in a sustainable way. The application of beneficial microorganisms could be a valuable alternative to achieve this objective. Several soil microorganisms that possess plant growth promotion have been reported. These microorganisms could improve crop productivity by enhancing nutrient uptake, nutrient cycling, nitrogen fixation, phytohormone production, and resistance against abiotic and biotic stresses [13]. Therefore, identifying and studying these beneficial microorganisms would help develop microbial formulations or consortia for improving crop productivity through low-cost sustainable biotechnology. Here, we provide an overview of microbiome engineering and plant biostimulants (PBs) and discuss how microbiome engineering and biostimulants can mitigate environmental stress and improve declining crop production.

\section{Plant microbiome engineering}

Growing recognition and appreciation of microbial diversity and function has encouraged rapid advances in microbiome research. Microbiomes are critical in the food production system due to their potential benefits in improving environmental health and protecting crops from pathogen attacks [14]. The root microbiome (microbial communities present in plant roots and the rhizosphere) is the primary determinant for these beneficial effects. The root microbiomes can be engineered by soil conditioning (to improve the microbiome diversity, for example, the use of legumes to enrich native diazotrophic microorganisms) or substrates / non-microbial biostimulants (including new organic soil amendments and root exudates to attract the beneficial microbiota). Alternatively, inoculating microbial strains into a preexisting microbial to modify the structure of microbial communities could also be used to achieve such goals. However, how do plants harness the beneficial functions provided by the microbial community and, at the same time, combat microbial pathogens? 


\subsection{How do host plants recruit their microbiome?}

Plants can modify the soil environment for their growth and other plants. These so-called plant-soil feedbacks have been practised in agriculture, where the sequence of crops is rotated to improve soil conditions for crop yield and ensure environmental sustainability [15]. Soil microbiota is known to be involved in these plant-soil feedbacks. For instance, the accumulation of beneficial soil microorganisms, such as nitrogen-fixing bacteria, can enhance plant growth. However, while many studies have shown the beneficial effects of a few soil microorganisms on plant performance, the molecular basis of plant-microbe interactions remains to be uncovered.

\subsubsection{Plant-to-microbe signals}

Plants secrete various molecules from roots into the rhizosphere to support microbial activity or magnetize the diversity of soil microbiota. This secretion process is known as root exudation. Root exudates mainly consist of primary (sugars, amino acids, and organic acids) and secondary metabolites (flavonoids, glucosinolates and terpenes). Besides serving as the energy sources for microbial growth, root exudates can also modulate changes in the microbial communities by acting as signaling molecules [16]. These exudates allow plants to recruit specific microbial communities in their rhizosphere. This mutual communication determines the coexistence and performance of plants in agricultural systems. Root exudation is genetically regulated and can be influenced qualitatively and quantitatively by the plants' nutritional status, age, and growth stage [17]. For example, Chaparro et al. [18] reported that sugars were the most exuded compounds in the early developmental stage of Arabidopsis, whereas amino acids and phenolic compounds in older plants of 28-31 days were highly accumulated.

Previous studies demonstrated that plants could recruit a distinct microbiota from the surrounding soil microbiome and induct them as plant endophytes [19,20]. However, the composition of endophytes is influenced by the plant species, genotype, and growth-stage [21]. Different plants might have distinct endophytes that might influence the plant tolerance to environmental stresses or nutrient-poor soils. In general, many endophytes exhibit plant growth-promoting effects than the rhizosphere inhabitants.

\subsubsection{Microbe-to-plant signals}

Many soil microorganisms are capable of synthesizing volatile organic compounds (VOCs). Microbial VOCs are microbeto-plant signal molecules, having small molecular masses (on average $300 \mathrm{Da}$ ) and low boiling points [22]. VOCs produced by microorganisms can regulate the plant physiological and metabolic processes to promote plant growth and improve stress tolerance. The function of microbial VOCs in promoting plant growth was first reported by Ryu et al. [23]. The authors showed that VOCs emitted by Bacillus subtilis GB03 increased the total leaf area in Arabidopsis thaliana and confers salt tolerance by downregulating HKT1 expression in roots, thus decreasing $\mathrm{Na}^{+}$accumulation. Since then, many studies have been carried out to determine the plant response to microbial VOCs. For example, tetrahydrofuran-3-ol, 2-heptanone and 2-ethyl-1-hexanol emitted by Bacillus sp. stimulate growth on A. thaliana and tomato [24] and dimethyl disulphide emitted by Pseudomonas stutzeri increases growth on tomato [25]. These findings demonstrated that microbial VOCs could be alternative strategies for improving crop yields with reduced synthetic fertilizer inputs, thus contributing to global food security. However, despite the emerging evidence suggesting that microbial VOCs could be an eco-friendly solution in agriculture, there is still lacking studies in applying VOCs in agricultural systems. Furthermore, the mode of action modulated by microbial VOCs on the plant performance has yet to be clarified.

Phytohormones are essential for plant growth and development and adaptation to environmental stresses. They are also involved in belowground interaction between roots, soil, and the microbiome. Phytohormones can be grouped into auxins, cytokinins, abscisic acid, gibberellins, salicylic acid, jasmonic acid, ethylene, strigolactone, and brassinolide, based on their chemistry and mode of action [26]. These phytohormones play significant roles in regulating root activity, microorganisms or their interaction with each other or with soil. For example, many plant growth-promoting rhizobacteria (PGPR) produce indole-3-acetic acid (IAA) that could influence root growth and architecture [27]. However, its effects are dependent on the endogenous IAA level in plants [28]. Besides involving in the belowground, the secreted microbial phytohormonal signals could enter the xylem channel via the plant roots and finally exert their functions on aboveground organs [29]. These phytohormones usually interplay with each other in coordination or an antagonistic manner in the root-soil continuum [30]. Figure 1 shows an overview of the plant's perception of external stimuli and defence mechanisms in response to abiotic and biotic stresses. 


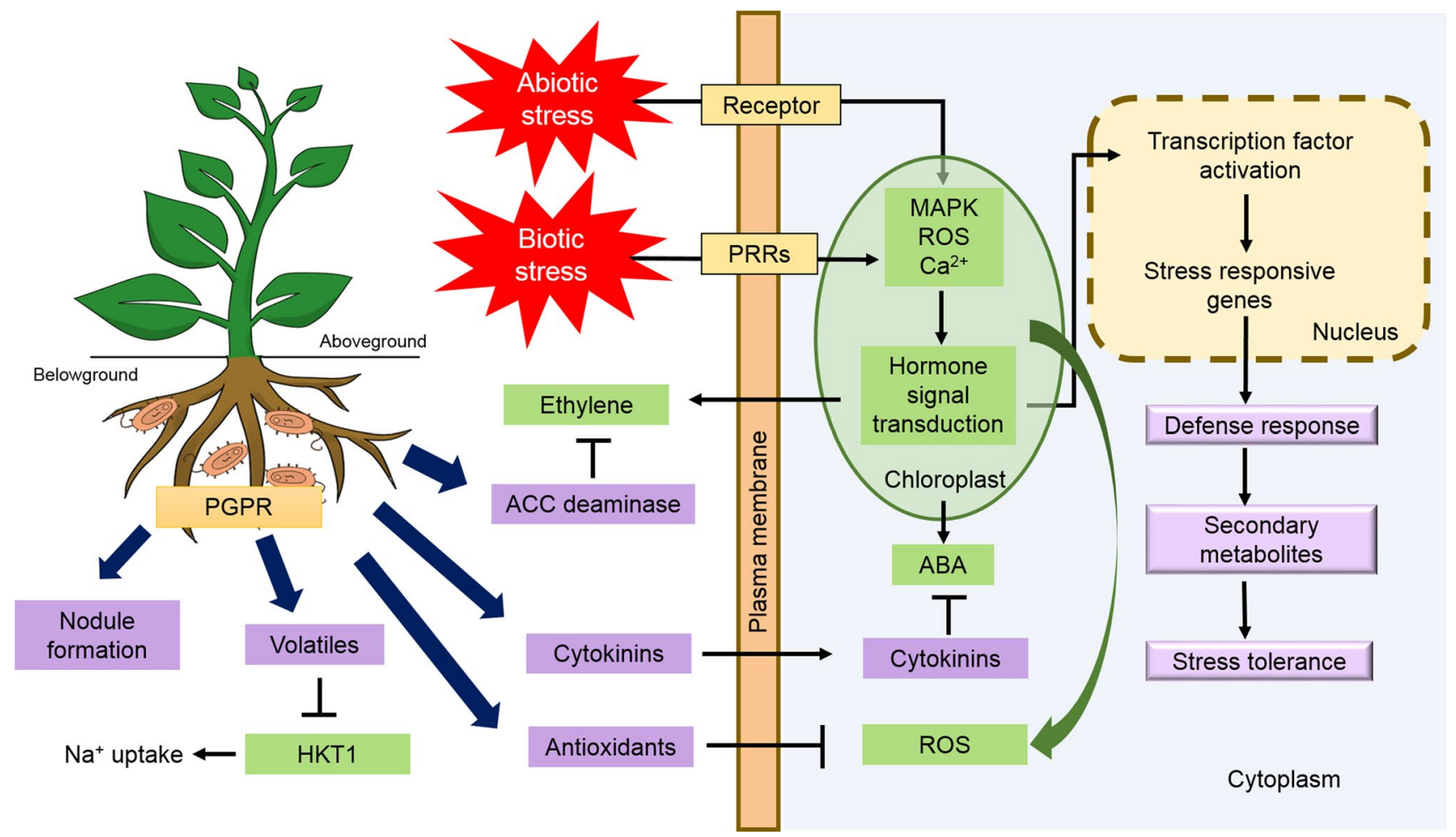

Fig. 1 An overview of the plant's perception of external stimuli and defence mechanisms in response to abiotic and biotic stresses. Arrows indicate promotion; blunt-ended lines indicate inhibition. ABA: abscisic acid; $\mathrm{Ca}^{2+}$ : calcium ion; high-affinity $\mathrm{K}^{+}$transporter 1: HKT1; MAPK: mitogen-activated protein kinase; PGPR: plant growth-promoting rhizobacteria; PRRs: Pattern recognition receptors; ROS: reactive oxygen species

\subsection{Microbiome engineering approaches}

Transferring one or more microbial species to plants that lack them might be the way to reduce plant disease susceptibility, increase nutrient availability, improve abiotic stress tolerance, and ultimately increase crop yields [31]. This is because microbial species may help fix atmospheric nitrogen, solubilize phosphate, produce phytohormones or enzymes that can modulate plant growth and development, and induce resistance systems against pathogens [32].

There are two approaches to engineer the plant microbiome: direct inoculation of exogenous beneficial microorganisms and re-inoculation of ex-situ enriched indigenous beneficial microorganisms. Direct inoculation of exogenous microorganisms with antagonistic activities against phytopathogens is the most common strategy to enhance the crop microbiome [31]. Even though inoculating exogenous microorganisms may not directly promote plant growth, they could benefit the plants by recruiting other microbial species known for their plant growth-promoting abilities [14]. For example, the inoculation of Streptomyces rochei IT20 had resulted in a higher a-diversity of the rhizospheric bacterial community and a relatively high abundance of other prolific plant growth-promoting Actinobacteria [33]. Another strategy for altering the crop ecosystems is to selectively enrich the indigenous beneficial microbial populations and re-introduce them back to the microbial community [14]. One of such examples has been reported by Awla et al. [34]. The authors found that the enriched indigenous Streptomyces sp. UPMRS4 can prime the rice crops against Pyricularia oryzae, reducing blast disease severity by $67.9 \%$. Similarly, Wu et al. [35] demonstrated that the enriched indigenous Pseudomonas mosselii BS011 could effectively prevent rice blast disease caused by Magnaporthe oryzae.

\subsection{Microbiome engineering in enhancing nutrient use efficiency}

Synthetic fertilizers are widely applied to agricultural systems to increase crop yield. However, synthetic fertilizers readily absorbed by the plants are susceptible to leaching and require frequent applications. For example, Fukamachi 
et al. [36] reported that less than $0.1 \%$ of chemical pesticides reach their biological targets, which means the remaining amount is leached into surrounding soil and water. Although some fertilizers consist of natural organic matter, such as composted organic waste, which is not prone to leaching, they are not readily absorbed by the plants [37]. Nitrogen fertilizers, a vital nitrogen supplement in our crop production systems, could directly or indirectly contaminate the environment through eutrophication and toxic deposition in groundwater if ineffective excessive use. About $50 \%$ of added nitrogen could be recovered by cropping systems [38], whereas another $50 \%$ remains in the soil as organic complexes or escapes through volatilization, leaching and runoff [39]. Hence, sustainable alternatives should be explored to enhance nitrogen use efficiency and reduce the fertilizer inputs to some extent.

Microbial biofertilizers relying on the stable cooperation of the enriched hydrolytic producers with host plants could mineralize, solubilize, or mobilize nutrients from organic matter while modulating the microbial community through competitive nutrient exclusion $[40,41]$. Hence, their application has attracted much attention from scholars and practitioners. The phytomicrobiome, perhaps not all, could reduce the nitrogen supplement applications by fixing atmospheric nitrogen through legume-rhizobium interaction or assisting the nitrogen fixers through their secretions [42]. There are two nitrogen fixers based on their association developed with plants: the symbionts and the free-living nitrogen fixers. Several symbiotic nitrogen fixers have been identified, including Allorhizobium, Azoarcus, Azorhizobium, Bradyrhizobium, Burkholderia, Frankia, Mesorhizobium, Rhizobium, and Sinorhizobium [43]. For free-living nitrogen fixers, the more notable ones are Azoarcus, Azospirillum, Azotobacter, Gluconacetobacter, and Herbaspirillum [44]. The application of beneficial phytomicrobiome on food crops has been extensively investigated. For instance, Yang et al. [45] found that soil application of microbial biofertilizer significantly increased wheat production while reducing the amount of chemical fertilizer required and enhancing the soil phosphorus and potassium availability. Erdemci [46] demonstrated that wheat seeds pre-coated with microorganisms showed improved growth and yield. Nonetheless, although the exogenous microbial inoculations had increased soil nutrients up to 90 days, the beneficial impact of microbial biofertilizers may decrease over time [47].

\subsection{Microbiome engineering in improving abiotic stress tolerance}

Abiotic stresses, such as drought, extreme temperature, and salinity, severely decrease the yield of food crops worldwide. When plants are exposed to abiotic stress, their internal metabolisms are disrupted, causing the imbalance between reactive oxygen species (ROS) production and scavenging systems [48]. The accumulation of excessive ROS can cause oxidative stress that leads to cell death and senescence. To survive, plants undergo a series of morphological, physiological, biochemical, cellular, and molecular changes [49]. Advances in omics and molecular technologies have identified signaling and regulatory pathways and characteristics of mechanisms underlying plant stress responses, providing valuable data in the information pool for crop improvement.

Implementing a sustainable strategy to enhance crop tolerance against abiotic stresses is of great importance to increase global food production. Several studies have shown that microbiome engineering could reduce plant oxidative stress by producing microbial 1-aminocyclopropane-1-carboxylic acid (ACC) deaminase to modulate plant ethylene stress hormone [20,50]. Plants synthesize ethylene via the actions of ACC synthase to produce ACC, an ethylene precursor. However, a high level of ethylene may inhibit their root elongation. Soil microbiota that produces ACC deaminase can degrade plant-produced ACC, resulting in reduced ethylene levels in the plants (Fig. 1). In this context, bacteria may act as a biological agent to control ethylene levels. For instance, ACC deaminase-producing rhizobacteria improved drought stress in pulse crops [51] and velvet beans [52]. Another study showed that microorganisms isolated from roots of grapevine and olive plants growing under severe drought conditions could improve the growth of another host species [53]. This promotion might be due to the more extensive root system stimulated by the bacteria that increased plant water uptake ability. This strategy holds promising benefits to save time, effort and costs. Yoolong et al. [54] demonstrated that Oryza sativa cv. KDML105 roots inoculated with the ACC deaminase-producing Streptomyces venezuelae ATCC 10712 prior to salt stress showed increased salt tolerance than the uninoculated rice.

Phytomicrobiome has demonstrated the capability to mediate host osmotic adjustment, including altering the composition of amino acids and sugars and facilitating the production of proline, polyhydric alcohols, glycine betaines, and osmolytes [55]. The microbial osmolytes work synergistically with those produced by plants to maintain plant health. Inoculation of osmotic-stressed crops with PGPR strains has been shown to increase glycine betaine content than those without inoculation. For instance, Gou et al. [56] found that maize inoculated with Klebsiella variicola F2, Raoultella planticola YL2, and Pseudomonas fluorescens YX2 produced a higher accumulation of glycine betaine and choline than control, resulting in improved water relations and plant growth under drought conditions. Another study by Kanwal et al. 
[57] showed that applying a combination of PGPR, compost, and mineral fertilizer increased soluble sugar and proline contents, which helped maintain membrane stability and water potential under stressful conditions. Taken together, inoculating beneficial microorganisms, especially those containing ACC deaminase, in farmland could help crops contend with abiotic stress and its associated detrimental effects on plants, thus increasing current agricultural outcomes.

\subsection{Microbiome engineering to improve biotic stress tolerance}

Biotic stress caused by bacteria, fungi, viruses, and nematodes poses immense global challenges to crop production. Most farmers rely on chemical pesticides or fungicides to control crop diseases. While these chemical agents effectively protect against crop diseases, their potential adverse effects on the soil ecosystem and the environment may not be reversible. Increasing evidence indicates that microbiome engineering possesses a great potential to combat phytopathogens. They are safe for humans and the environment and easily degraded in soil. These engineered microbiomes are applied to plants to suppress the growth of the pathogenic population [58], as shown in several major crops, such as rice, wheat, and corn. For instance, Saikia et al. [59] demonstrated that exogenous microbial inoculations either in soil or as endophytes could combat Xanthomonas blight in rice. Recent studies suggest that plants respond to biotic stress by altering their root exudation chemistry to attract health-promoting microbiomes. For example, 89 primary metabolites in cucumber roots infected with pathogenic Fusarium oxysporum were differentially changed compared to roots colonized by beneficial Bacillus amyloliquefaciens [60]. Besides primary metabolites, secondary root metabolites are also equally important since they are often induced during pathogen attacks. For instance, $\mathrm{Xu}$ et al. [61] reported that strigolactone was highly accumulated in parasitic nematodes-infested tomato roots.

The effectiveness of PGPR strains as single strains or as a consortium in pathogen biocontrol has been evaluated. It is believed that consortia are more effective at controlling biotic stress than single inoculants [62], although some studies indicate the contrary. In a consortium, microbial species may exhibit synergistic interactions and confer benefits to each other [63]. Some strains may produce secondary metabolites, such as exopolysaccharides, to render the non-producing strains resistant to stress or degrade substrates into forms that other consortium members can use. This probably could explain why ineffective strains are more effective in a consortium. Santhanam et al. [64] reported that Bacillus megaterium B55 and Pseudomonas azotoformans A70, with insignificant effects on mortality reduction in sudden wilt pathogensinfected tobacco, performed better in a consortium with other five bacteria. On the other hand, some PGPR may be more efficient as single strains [62]. Hence, further research is required to draw a conclusion. These findings suggest that microbiome engineering could be potentially complement existing biotic stress management practices in agriculture, such as crop rotation, breeding, and biotechnology.

\subsection{Limitations and concerns}

Deploying microorganisms to increase crop productivity is an attractive approach. Nevertheless, the outcome of the response is not always encouraging due to several limitations. For instance, the signals used by plants to recruit beneficial microbiota can be hijacked by parasitic organisms. One such example has been discussed, where pathogenic nematodes can exploit the exudation of arbuscular mycorrhizal fungi (AMF)-recruiting strigolactones to locate their host [65]. Moreover, the effectiveness of exogenously applying microorganisms in establishing a beneficial environment to both entities is dependent on whether these exogenous microorganisms can survive in the competition with the indigenous microorganisms [66]. Fortunately, their persistence can be enhanced by inoculating crops with consortia instead of single strains. While this approach increases the survival and activity of the inoculated microbiota, the interactions of these pioneer exogenous microorganisms with the microclimate (temperature and humidity), surface structure $(\mathrm{pH}$, water, and nutrient availability), host plants (exudates and defense mechanisms), and the indigenous microorganisms (exudates and competition) should also be taken into considerations [19,66, 67].

The composition of the synthetic microbiomes can be tailored for specific traits, but currently, only culturable microbial taxa can be incorporated as part of the synthetic microbiome [68]. The current limitation of isolating novel indigenous microorganisms is confounded by the fact that most natural microbiomes remain uncultivated [69]. Alternatively, alteration of soil microbial community can be achieved by introducing genetically modified microorganisms that have been designed to be resilient in adverse conditions while possessing plant growth-promoting traits or introducing desired traits into the targeted microbial community in situ via horizontal gene transfer [70]. Nonetheless, introducing genetically modified microorganisms or exogenous genes into the open environment requires stringent national biosafety regulations. 


\section{Plant biostimulants}

PBs have been considered promising and environmental-friendly innovation agronomic tools, as shown by the increase of scientific publications (see bibliometric analysis in Sect. 3.5) and the constant expansion of their market [71]. Therefore, they are among the hot topics in agriculture and have been extensively reviewed [72-75]. In this section, we report recent literature data concerning PBs application and achievements to advance crop production and quality.

\subsection{Definitions and their regulations}

The definition of PBs has been rigorously debated over the last decade. Over the past few years, several types of PBs have been defined by different authors based on the composition of the products, source material, and mode of action. However, the efficacy of PBs is not due to a single compound, making it complicated to understand which compounds are the most active and what their mode of action is. Therefore, the European Commission noted the need to repeal the existing Fertilizers Regulations and expand the scope to other organic products, including PBs.

Specifically, PBs are any substances or microorganisms applied to plants to facilitate the uptake of nutrients, enhance environmental stress tolerance, and expand crop quality traits along with a good yield [76]. They were first defined by Zhang, Schmidt [77] as "materials that, in minute quantities, promote plant growth". Here, the term "in minute quantities" differentiates the PBs from nutrients, soil improvers, and pesticides applied in larger quantities. Before adopting Regulation (EU) No 2019/1009 [78], PBs were defined by what they are not to differentiate PBs from fertilizers and pesticides. The PBs were redefined in the Fertilizing Products Regulation (FPR) as "EU fertilizing products stimulating plant nutrition processes independently of the product's nutrient content with the sole aim of improving one or more of the following characteristics of the plant or the plant rhizosphere: nutrient use efficiency, tolerance to abiotic stress, quality traits, availability of confined nutrients in soil or rhizosphere" [78]. The new definition clarifies the categorization of PB products. While removing them from the Plant Protection Products Regulation, PBs remain in the scope of Regulation (EC) 1907/2006 [short for the Registration, Evaluation, Authorisation, and Restriction of Chemicals (REACH)] [79]. These new regulations aim to improve internal market operations for fertilizer products in the European Union, boost investment and promote effective and safe fertilizers [80].

\subsection{Source of plant biostimulants}

As previously mentioned, PBs can be formulated with diverse microorganisms or naturally occurring bioactive compounds. They do not provide nutrients to plants and do not target pests and pathogens, but they encourage nutrient uptakes or help foster plant growth and development. PBs have been classified based on their mode of action [81], contents [82], or a combination of both [83]. However, under the FPR, PBs are classified into two categories: microbial PBs and non-microbial PBs.

\subsubsection{Microbial plant biostimulants}

The availability of high-quality agricultural lands has decreased over the past several decades and is likely to continue to do so as climate change progresses. This indicates that crop yields will need to be maintained under more stressful conditions despite production on a smaller land area. Microbial PBs have been widely used to enhance crop yield under low-input conditions and mitigate the impacts of climate change on crops [84]. They contain free-living beneficial bacteria and/or fungi listed in the Component Material Categories, number $7[75,85]$. Many bacteria and fungi have been explored for their potential to be applied as biostimulants. Of these, Rhizobium and rhizospheric PGPR are the major reported group [86]. To date, more than 20 commercially available microbial PBs are derived from PGPR. Besides PGPR, AMF have also been used to enhance plant performance. AMF are early symbiotic partners of many plant species. More than $80 \%$ of land plant species could form symbiotic associations with AMF [87]. Similar to PGPR, some AMF inoculants have been commercialized by companies using either single or mixtures of AMF species, mostly are Funneliformis mosseae and Rhizoglomus irregulare [88]. 


\subsubsection{Non-microbial plant biostimulants}

Non-microbial PBs consist of bioactive substances, including humic substances, protein hydrolysates, nitrogen-containing compounds, seaweed extracts, chitosan, biopolymers, and inorganic compounds. They comprise more than $33 \%$ of the biostimulant market worldwide [89]. Of these, seaweed extracts are the most commonly used [90]. Seaweeds are highly nutritious. They are rich in proteins, enzymes, and polysaccharides. The application of seaweed extracts in agricultural farms has been reported during the first century [91]. Currently, seaweed extracts have been applied to plants to mitigate abiotic stress, enhance nutrition efficiency and improve root growth and microbial activity of the root zone [74]. Seaweeds can be categorized into three groups based on their pigmentation: (i) Phaeophyta (brown), (ii) Rhodophyta (red), and (iii) Chlorophyta (green) [92]. Commercially available seaweed extracts are mostly from brown seaweeds, such as Ascophyllum, Fucus, and Laminaria [93]. This is probably due to their wide range of beneficial organic and mineral components, such as laminarin, fucoidan and alginates, mannitol plant hormones, and minerals ( $\mathrm{Fe}, \mathrm{l}, \mathrm{K}, \mathrm{Mg}$, and S) [94].

Humic and fulvic acids are organic molecules generated from the biological or chemical transformation of plant and animal wastes and chemical reactions. The physiological changes in roots and shoots, thanks to the exogenous application of humic substances, allow crops to better assimilate and distribute nutrients and thus, improve their growth and stress tolerance. Humic substances are commonly applied through soil drenching, while some are applied through foliar application. The beneficial effects of humic substances include (i) improving soil structure, (ii) improving the availability of phosphorus, (iii) neutralizing soil pH, (iv) inducing lateral root growth, and (v) stimulating nitrate assimilation in crops [95]. However, how do humic substances influence plant physiology is still unknown. This is due to the complexity of these substances and different plant responses altered by their application.

Protein hydrolysates are also commonly used as PBs in agriculture to help crops cope with environmental stresses. This class of PBs contains a mixture of free amino acids, oligo- and polypeptides derived from plant sources and animal wastes. They are mainly applied as a foliar spray and, in some cases, as a substrate drench or seed treatment. Protein hydrolysates have been shown to exhibit biostimulatory activity by (i) inducing several key enzymes involved in nitrogen assimilation and carbon metabolism and (ii) increasing antioxidant enzyme activity and secondary metabolite production [96].

\subsection{Application of plant biostimulants}

PB formulation could be applied directly to the soil, incorporated with compost, or combined with fertilizers and micronutrients either alone or combined with other types of PBs to synergize the positive effects on plants [97]. PBs, such as seaweed and other plant extracts, are often used in the form of foliar applications, whereas PBs containing humic substances are often applied directly onto the soil. The best time to apply PBs is in the morning since plant stomata are open and the assimilation rate is at its peak [98]. Some examples of PB application on food crops are listed in Table 1.

\subsubsection{Plant biostimulants for crop growth and improvement}

The stimulation effects of PBs on seed germination, plant growth, and crop productivity have been reported. Ertani et al. [125] evaluated the capacity of seaweed extracts to stimulate the growth of maize. Among the six seaweed extracts, Ascophyllum nodosum extract was the most efficient in promoting root growth, likely due to its elevated indole-3-acetic acid content [125]. Foliar or soil application of organic acid-based (citric acid, gluconic acid, and humic acid) and potassiumrich PBs on submerged rice have enhanced nutrient use efficiency and photosynthetic pigment contents [103]. Kundu et al. [103] found that foliar spraying of organic potassium humate together with soil application of inorganic potassium sulfate had produced the highest rice straw ( $22.4 \mathrm{~g} / \mathrm{kg}$ soil) and grain yield ( $5.6 \mathrm{~g} / \mathrm{kg}$ soil). Billard et al. [126] found that the increase in nutrient acquisition might be due to the upregulation of the transporter genes. Besides enhancing nutrient use efficiency, seaweed extract treatments also increased the plant biomass and bioactive molecules, such as phenolics and flavonoids [127]. These enhanced phenolics and flavonoids might be due to the upregulation of glutathione reductase and ascorbate peroxidase [127].

In potatoes, Ekin [101] found that the application of PBs containing humic acid and PGPR (B. megaterium and B. subtilis) increased the plant height $(71.7 \%)$, the number of tubers per plant $(15.2 \%)$, and the tuber weight $(118.8 \%)$ as well as promoted industrial-grade tuber yield (294.4\%) compared to untreated control. In addition, PBs promote stomatal conductance and stomatal density, which are correlated with positive regulation of EPFL9 [128], enhancing internal carbon 


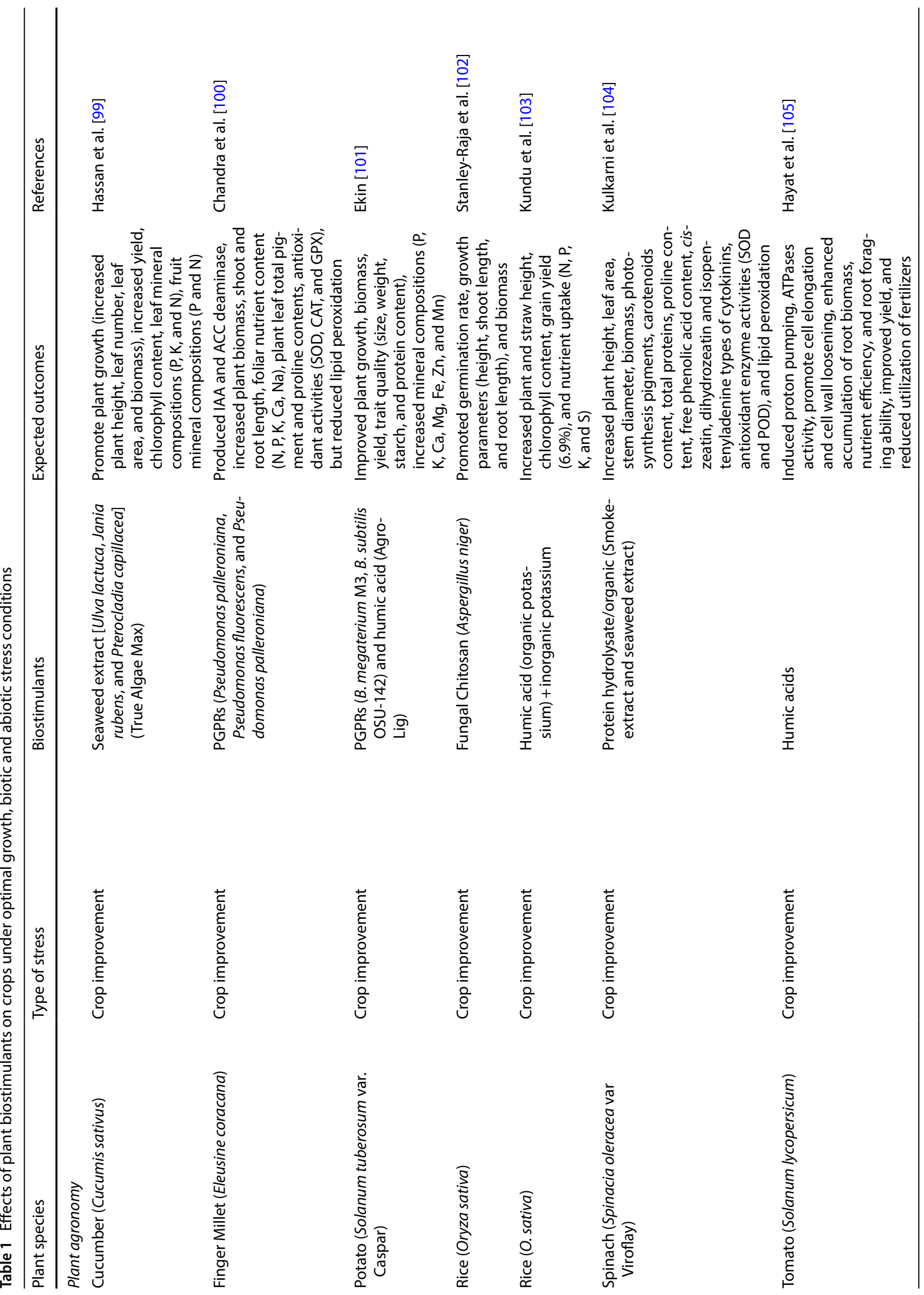




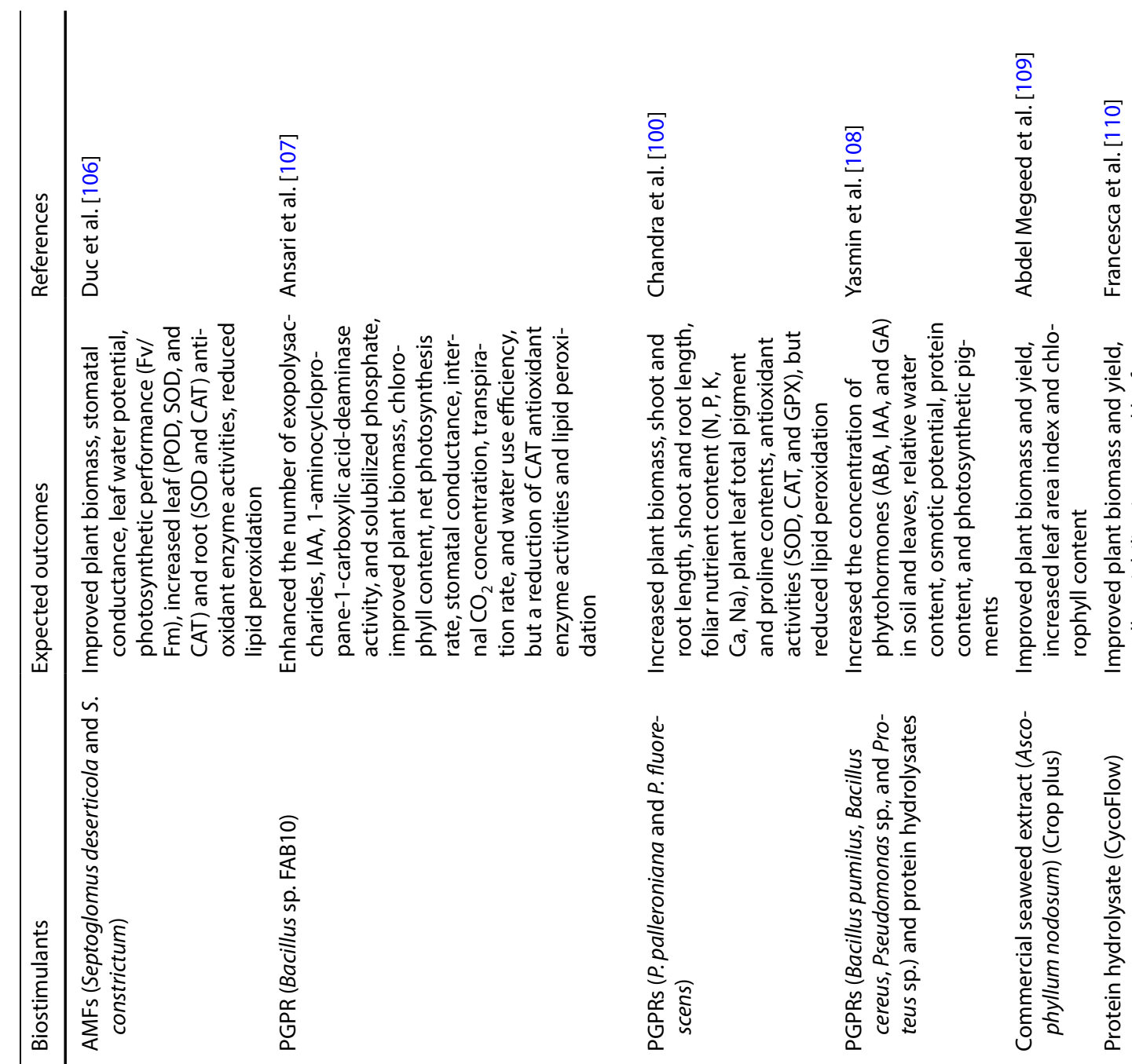

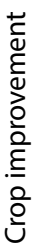

$\frac{+}{5}$
$\frac{5}{0}$
ํํำ

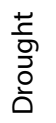

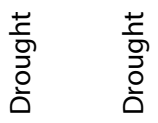

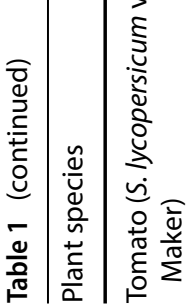

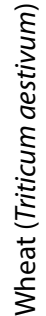

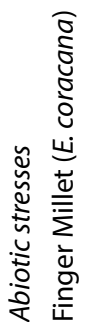

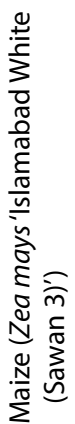

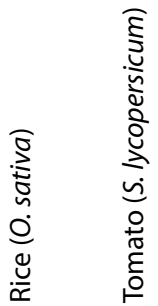




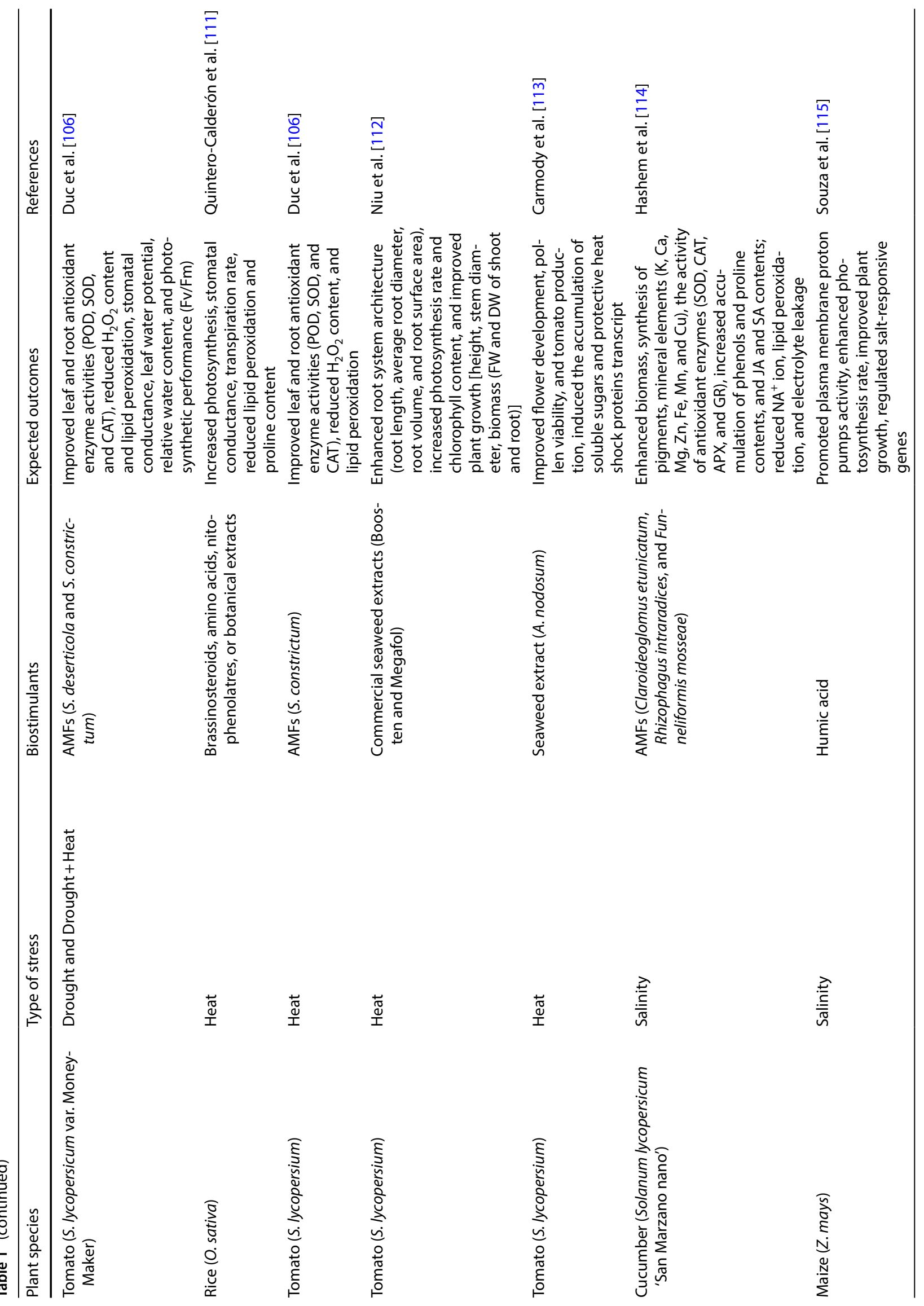




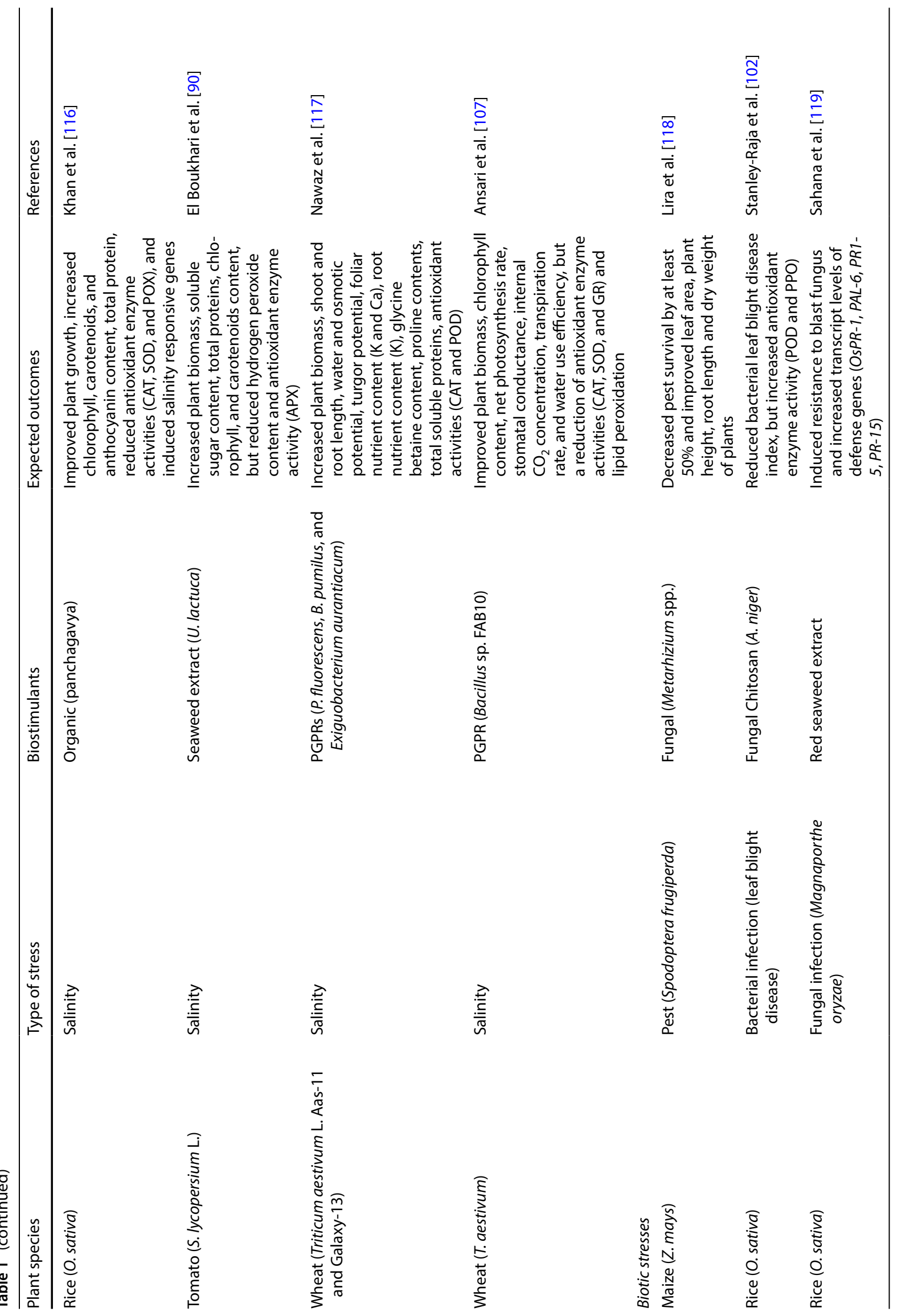




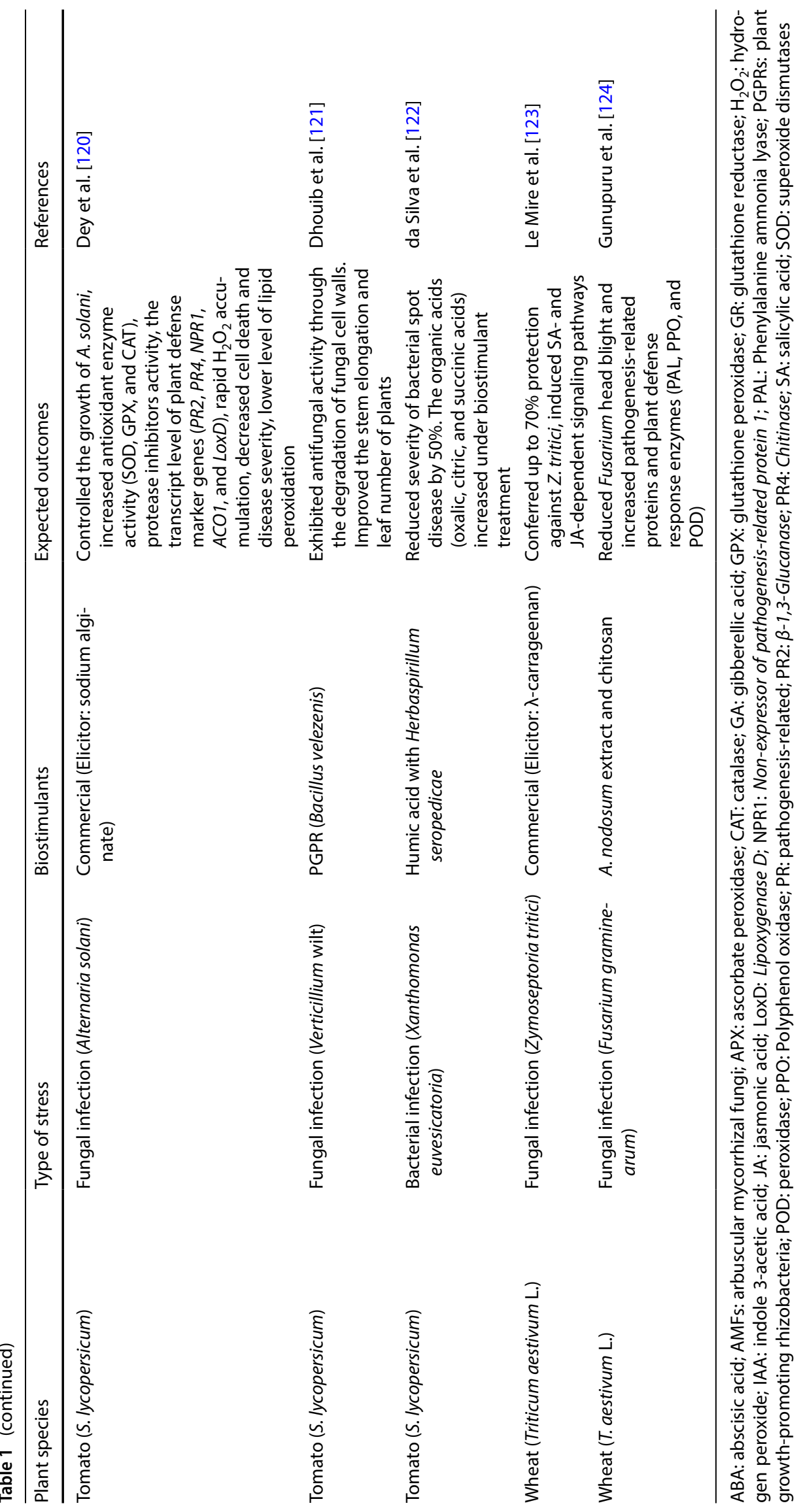


dioxide concentration, thereby improving plant photosynthesis, and leading to yield increment [107]. For example, chitosan biostimulants have been shown to increase the height, root length and biomass in rice [102]. These findings suggest that PBs are a promising biotechnology tool to improve plant growth, yield, and quality in field conditions [101].

\subsubsection{Plant biostimulants in mitigating abiotic stresses}

Plants are subjected to various abiotic stresses. The detrimental effects of these stresses are responsible for $70 \%$ of the yield gap dictated by climate changes [129]. Therefore, to increase crop productivity, the utilization of PBs in agronomic production systems has been suggested as one of the promising drivers toward further yield stability. PBs protect plants against abiotic stresses through activating a cascade of signaling activity, increasing enzymatic and non-enzymatic antioxidant activities, reducing the level of lipid peroxidation and electrolyte leakage, and enhancing water use efficiency, nutrient use efficiency, and photosynthesis activity $[110,114]$. Several key genes involved in antioxidant metabolism (CAT , SOD, POD, APX, GPX, GR, CHS, CSD1, and DHAR), biosynthesis and signaling of abscisic acid (NCED), aquaporin (PIP1 and $P I P 2)$, osmoprotectant (P5CS1), and secondary metabolite biosynthesis (PAL) showed differential expression patterns [130].

3.3.2.1 Drought stress Drought stress poses a severe threat to food security by affecting crop yields and product quality. In this regard, PBs have been applied in agriculture to increase crop tolerance to drought stress. For example, foliar application of commercial seaweed extracts (Crop Plus) to the drought-stressed Sakha108 rice cultivar produced higher leaf area index, chlorophyll content, and biomass compared to cytokinin and abscisic acid. The Crop Plus-treated rice showed $29 \%$ increment of dry matter production, $47 \%$ of the number of tiller $/ \mathrm{m}^{2}, 43 \%$ number of panicle $/ \mathrm{m}^{2}, 15 \%$ number of filled grain, $50-64 \%$ of panicle weight $/ \mathrm{g}, 15-18 \%$ of $1000-$ grain weight $/ \mathrm{g}$, and $33 \%$ of grain yield $\mathrm{t} / \mathrm{ha}$ [109] when compared to non-treated plants. In drought-stressed tomato plants, the application of AMF biostimulants increased 14\% root dry weight and $18 \%$ shoot dry weight compared to untreated tomato plants [105]. When analyzing the biochemical changes, Duc et al. [106] found that several antioxidant enzyme activities (catalase (CAT), superoxide dismutases (SOD), and peroxidase (POD)) in AMF-treated tomato plants were higher than untreated plants. However, the hydrogen peroxidase content and lipid peroxidation of AMF-treated tomato plants were significantly reduced. Similar studies have also been reported in various food crops, such as rice [131], wheat [132], tomato [133], maize [108], and finger millet [100].

3.3.2.2 Heat stress Heat stress is projected to increase in frequency in many regions as global temperatures rise. A recent study demonstrated that AMF biostimulants could modulate the oxidative stress caused by heat stress [106]. The authors reported that ROS production in heat-stressed tomatoes was reduced after the AMF treatment due to the enhanced antioxidant enzyme activities [106]. Another study showed that the foliar application of two commercially available seaweed PBs (Boosten and Megafol) alleviated the heat stress effect in tomato plants [112]. In terms of the root system, the authors found that Boosten produced a higher root length (41\%) and root diameter (89.8\%) than Megafol [112]. In aboveground tissues, Boosten increased the photosynthesis rate by $81.7 \%$ and chlorophyll content by $30.5 \%$ compared to non-treated tomato plants [112], suggesting that the foliar application of seaweed extracts could potentially enhance crop tolerance to heat stress.

3.3.2.3 Salinity stress The accumulation of high levels of salts in the soil causes salinity stress, affecting plant growth and yield. Similar to drought stress, salinity stress results in oxidative damage, but the application of PBs on plants could reverse this effect. For example, maize seeds primed with microbial PBs containing Bacillus sp. MGW9 increased the stress tolerance of the maize plants grown in saline-alkali soil [134]. When analyzing two contrasting (salt susceptible and tolerant) rice cultivars under salinity stress conditions, Khan et al. [116] found that the natural biostimulant panchagavya significantly enhanced biochemical and physiological characteristics in both cultivars. Both rice cultivars showed differential expression patterns for several salinity-responsive genes, including ATG1, ATG3, ATG4, ATG6, ATG7, ATG8, ATG9, BI-1, MAPK-1, WRKY53, CAT-1, SOD, and GPX [116]. Another study on rice observed an increase in the number of grains per spike (23.4\%), grain yield (g/1000 seeds) (10\%), grain protein (2\%), and straw yield (g/plant) (9\%) [107]. In wheat, Zou et al. [135] found that applying crude polysaccharides from brown seaweed enhanced the salinity tolerance of wheat seedlings. They indicated that the beneficial effects might be due to (i) decreased cell membrane lipid peroxidation, (ii) increased chlorophyll content and antioxidant enzyme activities, and (iii) a better efflux and compartmentation of intracellular ions. Other studies on applying PBs to reduce the deleterious effects of salinity stress have also been reported in several food crops, such as rice [136], maize [134], lettuce [137], cucumber [114], and tomato [90]. 


\subsubsection{Plant biostimulants in mitigating biotic stresses}

Besides abiotic stress factors, biotic stress caused by phytopathogens also influences crop productivity. In nature, plants are frequently exposed to biotic stress, which causes physiological, biochemical, and molecular changes involving physiological damages that could reduce their productivity. Consequently, plants have developed an advanced defense system to combat biotic stress. These include physical barriers, such as waxes and thick cuticles, to prevent pathogens from settling into the plant, the release of chemical compounds, pathogen-associated molecular patterns-triggered immunity, and plant resistance (R) proteins [138].

The application of PBs in agriculture encourages the healthy growth of crops and increases their productivity by suppressing pathogens and pests (Table 1). For example, the symptom of early blight disease caused by Alternaria solani [120] and tomato chlorotic dwarf viroid disease [139] in tomato plants was significantly reduced after pre-treated with sodium alginate or $\lambda$-carrageenan (an elicitor of commercial seaweed extracts) biopolymer. The $\lambda$-carrageenan has also been shown to confer up to $70 \%$ protection against Septoria tritici blotch disease by inducing salicylic acid- and jasmonic acid-dependent signaling pathways in wheat [123]. Rice seeds pre-treated with chitosan PBs showed enhanced tolerance against bacterial leaf blight (Xanthomonas oryzae pv. Oryzae) with a 39.9\% disease index [102]. The authors found that the antioxidant enzyme activities of the pre-treated rice seeds increased about 2.5- and threefold for POD and polyphenol oxidase, respectively [102]. de Oliveira Filho et al. [140] evaluated the cottonseed-derived protein lysates PBs on their ability to inhibit strains of Colletotrichum gloeosporioides and Staphylococcus aureus under in vitro conditions. They found that the heat-pretreated hydrolysates inhibited $73.9 \%$ C. gloeosporioides and $32.4 \%$ S. aureus [140]. Similar studies on applying different PBs on other crops, such as maize [141] and tomato [121], have also been reported.

The growth inhibition of pathogens by PBs occurs through the antibiosis action of VOCs, bacteriocin, and siderophore. Microbial PBs, such as PGPR, produce numerous antibiotics and VOCs with antagonistic activities. These compounds are effective agents against phytopathogens. For instance, B. subtilis (PGPR) emitted VOCs, particularly acetoin, that triggered induced systemic resistance (ISR) and reduced Arabidopsis plant's susceptibility to Pseudomonas syringae [142]. Further analysis showed that resistance to $P$. syringae occurs via an NPR1-dependent mechanism and involves salicylic acid and ethylene but not jasmonic acid [142]. Bacteriocins, an antimicrobial peptide produced by PGPR, can eliminate competitor strains or inhibit related bacterial species. The direct application of bacteriocins has effectively reduced bacterial spot disease symptoms on tomato fruits [143].

Some PBs can alter bacterial membrane permeability and inhibit biofilm formation, leading to cell death and reduced infection rates. For example, chitosan PBs at $500 \mathrm{mg} / \mathrm{ml}$ concentration inhibited $98 \%$ of Escherichia coli, Klebsiella pneumoniae, Pseudomonas aeruginosa, and S. aureus [144]. It is believed that chitosan disrupts bacterial cell membranes by increasing the permeability of the outer and inner membranes and causing membrane damage [145]. The exogenous application of chitooligosaccharides (a natural derivative of chitosan) on rice increased plant cell wall integrity and lignin formation, which prevents the entrance of the bacterial pathogen $X$. oryzae pv. Oryzae [146].

\subsection{Biostimulant market}

The market of PBs is increasing every year and is predicted to reach USD 5.6 billion in 2026, with a compound annual growth rate of $12.1 \%$ [147]. The growth of the market is attributed to the increasing impact of climate change, soil degradation, and abiotic stresses to crop production and the increase of organic farming due to the shift of the consumption pattern of consumers from non-organic to organic. Currently, fruits and vegetables account for the largest market share in the biostimulants market [147]. Other main crops on which biostimulants are applied include barley, wheat, rice, and oilseed rape. The main factors driving the increasing growth of the biostimulant market are perhaps because of (i) the increasing awareness of the need for sustainable alternatives to synthetic chemicals, (ii) the availability of PBs addressing specific agronomic needs, (iii) the increasing frequency of environmental stresses and (iv) changing of agricultural and environmental policies. Regarding the first aspect, PBs are generally recognized as a sustainable alternative to current agricultural practices [97]. Their low toxicity and the fact that they do not accumulate over the long term have made PBs an environmentally friendly option [73]. In terms of application methods (foliar spray, soil drench, and seed priming), foliar spray occupies a higher share of the global market than soil drench and seed priming [148]. However, seed pre-treatment with PBs occupies a higher share of revenues. Given that PBs have great potential to replace chemical pesticides, the industry has generally welcomed PB development opportunities. 


\subsection{Bibliometric analysis}

While the industry is a key player in promoting PBs, PBs have also received attention from the scientific community. Currently, more than 1,990 scientific papers focused on "biostimulants" or "biostimulant" have been published in the last ten years (2011-2021) (www.scopus.com). We compiled a list of relevant publications with the co-occurrence of terms in the title and abstract from six literature sources, including journal articles and conference proceedings. Once collected, bibliographic maps and networks were generated using the software VOSviewer, version 1.6.17 [149]. Our bibliographic search covered all biostimulant(s) articles published during 2011-2021. The eligibility criteria were set as follows: the terms repeated at least five times were selected, singular and plural forms were standardized to singular forms to avoid redundancies, and full names and abbreviations were standardized to full name. The maps and networks for the analysis are presented in Fig. 2. Based on these premises, 50 terms were used and clustered according to the strength of association between them. Four clusters were generated and integrated into a network overlay visualization map (Fig. 2).

The results show that "growth" and "yield" are the main terms. The terms "chlorophyll", "biomass", "photosynthesis", and "carotenoid" are strongly related to plant growth, indicating that these are crucial traits in plant growth. "PGPR" are the main PBs used for research concerning plant growth. "Seaweed extract" and "PGPR" are the PBs investigated concerning drought stress. Among abiotic stresses, "drought stress" is the main term, although "salinity" and "oxidative stress" were displayed. "Tomato" and "maize" are the main crop.

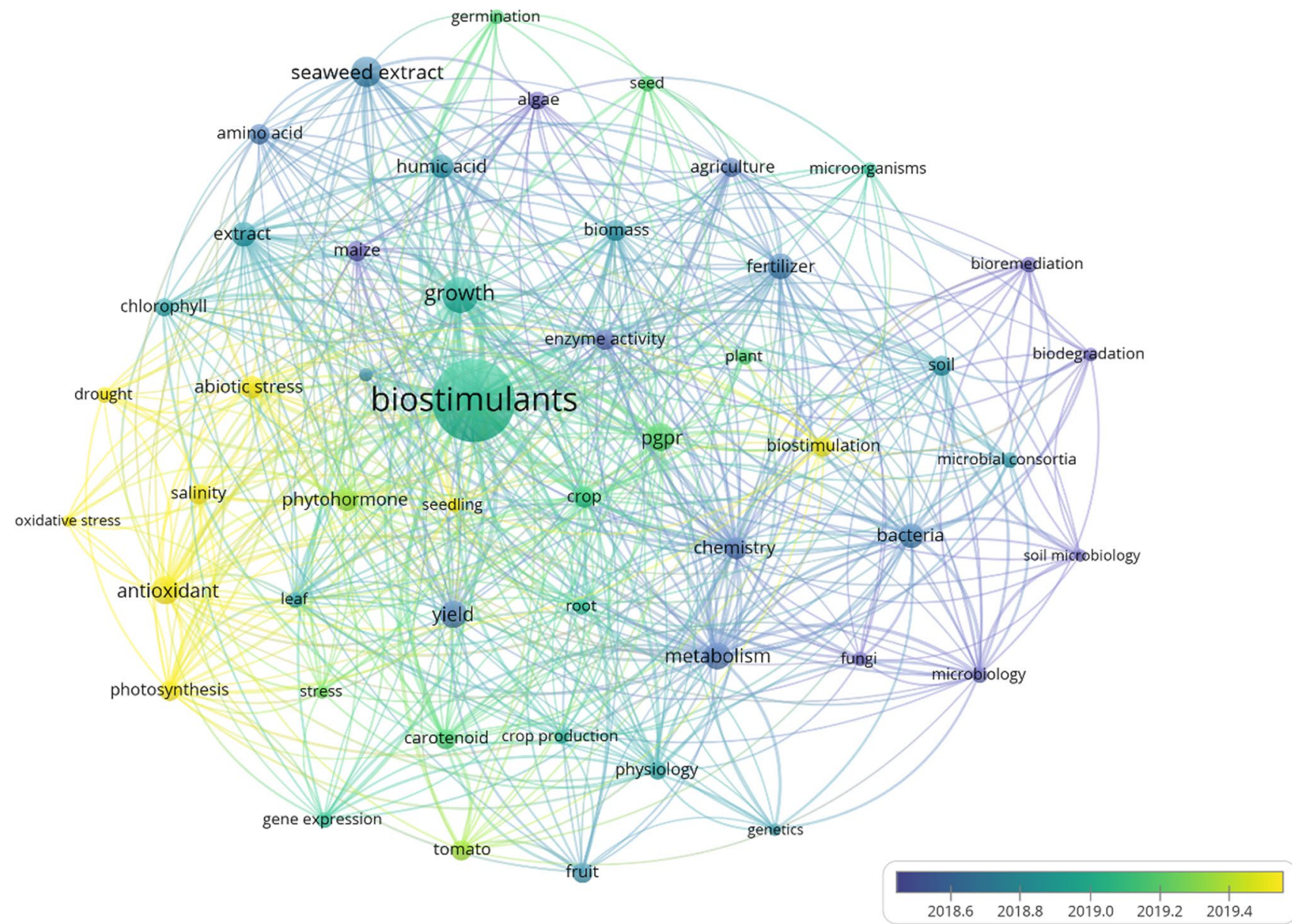

Fig. 2 Bibliographic maps and networks are based on the literature cited with the term "biostimulants". The size of the circles and font represents the frequency of term occurrence. The larger circles mean the greater the frequency. The lines are the linkage among terms. Their thickness represents the relative link strength, whereby the thicker lines have stronger relationships among terms 


\subsection{Limitations and concerns}

The application of PBs in agriculture has reduced the dependency on chemical fertilizers and pesticides [97]. Despite its potential, the use of PBs in agriculture has encountered several limitations and challenges. These include the complexity of plant physiological effects on PBs, the effectiveness of PB formulation in enhancing crop growth and stress tolerance, and the uncertainty of the current regulations. In addition, the composition and content of active substances used in PBs can be affected by many factors, such as agricultural land types, growing conditions, season, and species [150]. These have raised questions about: What are the molecular mechanisms underlying the biostimulatory action of PBs? What is the effective method, frequency, and time of PB application, and to what extent the crops applied may show beneficial effects? How long do the PBs effects persist? Indeed, this knowledge gap has impeded farming communities and industries from fully utilizing PBs in agronomic practices. Moreover, the existing laws on PBs are vague due to the unclear categorization of PBs. Different countries and states may have different categories or terminologies for PBs. Furthermore, in the absence of proper and clearer laws and regulations, the registration process of PBs becomes complicated and potentially creates a barrier to PB development. This may affect the manufacturers in positioning PBs on markets [82]. Hence, the involvement of farmers, the scientific community, stakeholders, and regulatory bodies are indispensable to realizing PBs for sustainable food production.

\section{Conclusion and future prospects}

Climate change has intensified the environmental stress on crops and increased the outbreak of plant diseases. Finding more sustainable and environmentally friendly alternatives to enhance crop yield and food quality and, at the same time, reduce the use of chemical fertilizers and pesticides is one of the most urgent tasks today. One promising and practical strategy is to harness beneficial plant-microbe relationships as a means to restore the plant ecosystem and increase crop productivity and stress tolerance (Fig. 3). The promotive effect of microbial consortia and PBs to mitigate the deleterious impacts of stresses on crop growth and yield have been reported for many years. Much evidence has demonstrated that a healthy crop microbiome and timely applications of PBs can restore soil health and productivity under low-nutrient input conditions and thus contribute to sustainable food production systems. However, microbial consortia and PBs are rarely included as part of commercial agricultural practices. The hindrance to adopting microbial consortia and PBs might be due to the insufficient baseline empirical data to model the risks and benefits of sustainable farming across multiple crop systems. Additionally, the farmers' hesitance to adopt the practice might be because of their lack of knowledge on the practical application of microbial consortia and PBs. The farmers' perspective against adopting microbial consortia and $\mathrm{PBs}$ is that using these products could increase cultivation costs.

Another major challenge for incorporating microbial consortia and PBs in crop improvement programs is the stringent regulatory frameworks and extensive risk assessment procedures on crop microbiomes. This might be because of the peculiarity of microbial consortia and PBs regarding their mode of action and the intended effects. Hence, a better understanding of the molecular and biochemical mechanisms of soil microbiomes and PBs with their host crops are required to fully exploit their benefits in crop improvement programs. This requires an intensive effort and interdisciplinary collaboration in microbial inoculant and PB development to bridge the gaps between research and practice and ultimately facilitate the diffusion of these bioproducts into the agricultural sector. In addition, continued investments in PBs research and product development are also a crucial driver of discovery in this realm. 


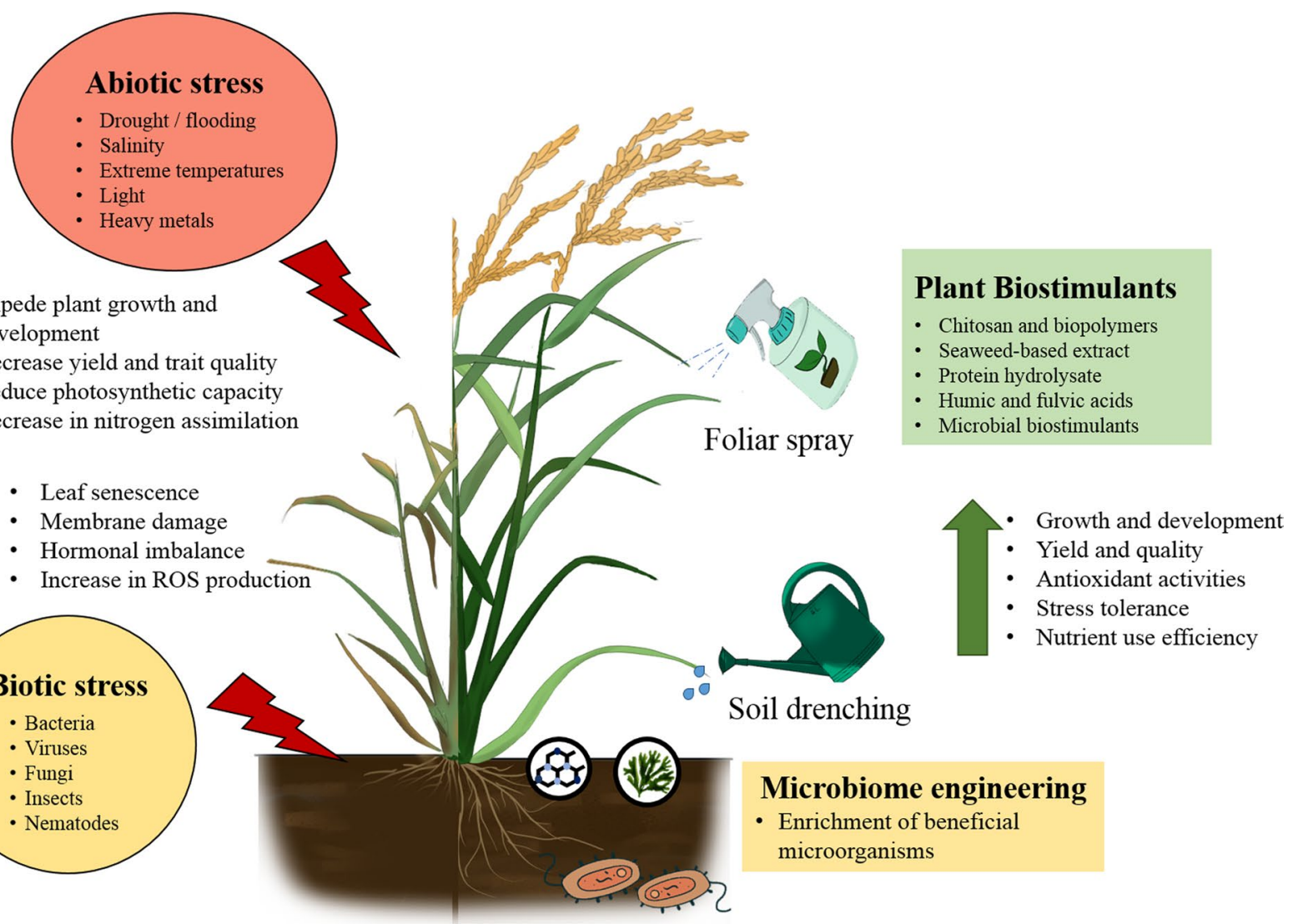

Fig. 3 Effects of different abiotic and biotic stresses on crop growth and development and the beneficial influence of microbiome engineering and plant biostimulants on crop plants

Authors' contributions BCT contributed to conceptualization. SL, WFAT, EYT, and BCT wrote the manuscript, with all authors commenting and critically revising previous versions of the manuscript. All authors read and approved the final manuscript.

Funding This research was funded by the Universiti Malaya RU Fund (ST003-2021; RU004A-2020).

Data availability Not applicable.

Code availability Not applicable.

\section{Declarations}

Competing interests The authors declare no competing interests.

Open Access This article is licensed under a Creative Commons Attribution 4.0 International License, which permits use, sharing, adaptation, distribution and reproduction in any medium or format, as long as you give appropriate credit to the original author(s) and the source, provide a link to the Creative Commons licence, and indicate if changes were made. The images or other third party material in this article are included in the article's Creative Commons licence, unless indicated otherwise in a credit line to the material. If material is not included in the article's Creative Commons licence and your intended use is not permitted by statutory regulation or exceeds the permitted use, you will need to obtain permission directly from the copyright holder. To view a copy of this licence, visit http://creativecommons.org/licenses/by/4.0/.

\section{References}

1. Popp J, Kovács S, Oláh J, Divéki Z, Balázs E. Bioeconomy: Biomass and biomass-based energy supply and demand. N Biotechnol. 2021;60:76-84. https://doi.org/10.1016/j.nbt.2020.10.004.

2. Gruda NS. Increasing sustainability of growing media constituents and stand-alone substrates in soilless culture systems. Agronomy. 2019;9(6):298. https://doi.org/10.3390/agronomy9060298. 
3. NOAA National Centers for Environmental Information (NCEI): U.S. Billion-Dollar Weather and Climate Disasters. https://www.ncdc.noaa. gov/billions/. 2021. Accessed 23 Nov 2021.

4. Mikecz O, Lombardi N, Markova G. Impact of natural disasters on crop and livestock production in developing countries. The impact of disasters and crises on agriculture and food security. Rome, Italy: Food and Agriculture Organization of the United Nations (FAO); 2018.

5. Brilli F, Loreto F, Baccelli I. Exploiting plant volatile organic compounds (VOCs) in agriculture to improve sustainable defense strategies and productivity of crops. Front Plant Sci. 2019;10:264. https://doi.org/10.3389/fpls.2019.00264.

6. Muzhinji N, Ntuli V. Genetically modified organisms and food security in Southern Africa: Conundrum and discourse. GM Crops Food. 2021;12(1):25-35. https://doi.org/10.1080/21645698.2020.1794489.

7. Ahmar S, Gill RA, Jung K-H, Faheem A, Qasim MU, Mubeen M, et al. Conventional and molecular techniques from simple breeding to speed breeding in crop plants: recent advances and future outlook. Int J Mol Sci. 2020;21(7):2590. https://doi.org/10.3390/ijms210725 90.

8. Chaudhary J, Deshmukh R, Sonah H. Mutagenesis approaches and their role in crop improvement. Plants. 2019;8(11):467.

9. Qaim M. Role of new plant breeding technologies for food security and sustainable agricultural development. Appl Econ Perspect Policy. 2020;42(2):129-50. https://doi.org/10.1002/aepp.13044.

10. Rani L, Thapa K, Kanojia N, Sharma N, Singh S, Grewal AS, et al. An extensive review on the consequences of chemical pesticides on human health and environment. J Clean Prod. 2021;283: 124657. https://doi.org/10.1016/j.jclepro.2020.124657.

11. UI Haq S, Boz I, Shahbaz P, Yildirim C. Evaluating eco-efficiency and optimal levels of fertilizer use based on the social cost and social benefits in tea production. Environ Sci Pollut Res. 2020;27(26):33008-19. https://doi.org/10.1007/s11356-020-09533-2.

12. Pandey C, Diwan H. Assessing fertilizer use behaviour for environmental management and sustainability: a quantitative study in agriculturally intensive regions of Uttar Pradesh. India Environ Dev Sustain. 2021;23(4):5822-45. https://doi.org/10.1007/s10668-020-00848-1.

13. Aamir M, Samal S, Rai A, Kashyap SP, Singh SK, Ahmed M, et al. Chapter 25 - Plant microbiome: diversity, distribution, and functional relevance in crop improvement and sustainable agriculture. In: White J, Kumar A, Droby S, editors., et al., Microbiome Stimulants for Crops. Woodhead Publishing; 2021. p. 417-36.

14. Orozco-Mosqueda MD, Rocha-Granados MD, Glick BR, Santoyo G. Microbiome engineering to improve biocontrol and plant growthpromoting mechanisms. Microbiol Res. 2018;208:25-31. https://doi.org/10.1016/j.micres.2018.01.005.

15. Hu L, Robert CAM, Cadot S, Zhang X, Ye M, Li B, et al. Root exudate metabolites drive plant-soil feedbacks on growth and defense by shaping the rhizosphere microbiota. Nat Commun. 2018;9(1):2738. https://doi.org/10.1038/s41467-018-05122-7.

16. Baetz U, Martinoia E. Root exudates: The hidden part of plant defense. Trends Plant Sci. 2014;19(2):90-8. https://doi.org/10.1016/j.tplan ts.2013.11.006

17. Malusà E, Pinzari F, Canfora L. Efficacy of Biofertilizers: Challenges to Improve Crop Production. In: Singh DP, Singh HB, Prabha R, editors. Microbial Inoculants in Sustainable Agricultural Productivity: Vol. 2: Functional Applications. New Delhi: Springer India; 2016. p. 17-40.

18. Chaparro JM, Badri DV, Bakker MG, Sugiyama A, Manter DK, Vivanco JM. Root exudation of phytochemicals in Arabidopsis follows specific patterns that are developmentally programmed and correlate with soil microbial functions. PLoS ONE. 2013;8(2):e55731. https://doi. org/10.1371/journal.pone.0055731.

19. Fitzpatrick CR, Salas-Gonzalez I, Conway JM, Finkel OM, Gilbert S, Russ D, et al. The plant microbiome: from ecology to reductionism and beyond. Annu Rev Microbiol. 2020;74(1):81-100. https://doi.org/10.1146/annurev-micro-022620-014327.

20. Arif I, Batool M, Schenk PM. Plant microbiome engineering: expected benefits for improved crop growth and resilience. Trends Biotechnol. 2020;38(12):1385-96. https://doi.org/10.1016/j.tibtech.2020.04.015.

21. Choi K, Khan R, Lee S-W. Dissection of plant microbiota and plant-microbiome interactions. J Microbiol. 2021;59(3):281-91. https://doi. org/10.1007/s12275-021-0619-5.

22. Fincheira P, Quiroz A, Tortella G, Diez MC, Rubilar O. Current advances in plant-microbe communication via volatile organic compounds as an innovative strategy to improve plant growth. Microbiol Res. 2021;247:126726. https://doi.org/10.1016/j.micres.2021.126726.

23. Ryu C-M, Farag MA, Hu C-H, Reddy MS, Wei H-X, Paré PW, et al. Bacterial volatiles promote growth in Arabidopsis. Proc Natl Acad Sci USA. 2003;100(8):4927-32. https://doi.org/10.1073/pnas.0730845100.

24. Jiang CH, Xie YS, Zhu K, Wang N, Li ZJ, Yu GJ, et al. Volatile organic compounds emitted by Bacillus sp JC03 promote plant growth through the action of auxin and strigolactone. Plant Growth Regul. 2019;87(2):317-28. https://doi.org/10.1007/s10725-018-00473-z.

25. Rojas-Solís D, Zetter-Salmón E, Contreras-Pérez M, Rocha-Granados MC, Macías-Rodríguez L, Santoyo G. Pseudomonas stutzeri E25 and Stenotrophomonas maltophilia CR71 endophytes produce antifungal volatile organic compounds and exhibit additive plant growthpromoting effects. Biocatal Agric Biotechnol. 2018;13:46-52. https://doi.org/10.1016/j.bcab.2017.11.007.

26. Lu Y, Wang E, Tang Z, Rui J, Li Y, Tang Z, et al. Roots and microbiome jointly drive the distributions of 17 phytohormones in the plant soil continuum in a phytohormone-specific manner. Plant Soil. 2021. https://doi.org/10.1007/s11104-021-04898-w.

27. Vacheron J, Desbrosses G, Bouffaud M-L, Touraine B, Moënne-Loccoz Y, Muller D, et al. Plant growth-promoting rhizobacteria and root system functioning. Front Plant Sci. 2013;4:356. https://doi.org/10.3389/fpls.2013.00356.

28. Backer R, Rokem JS, llangumaran G, Lamont J, Praslickova D, Ricci E, et al. Plant growth-promoting rhizobacteria: Context, mechanisms of action, and roadmap to commercialization of biostimulants for sustainable agriculture. Front Plant Sci. 2018;9:1473. https://doi.org/ 10.3389/fpls.2018.01473.

29. Borghi L, Liu G-W, Emonet A, Kretzschmar T, Martinoia E. The importance of strigolactone transport regulation for symbiotic signaling and shoot branching. Planta. 2016;243(6):1351-60. https://doi.org/10.1007/s00425-016-2503-9.

30. Jing H, Strader LC. Interplay of auxin and cytokinin in lateral root development. Int J Mol Sci. 2019;20(3):486. https://doi.org/10.3390/ ijms20030486.

31. Quiza L, St-Arnaud M, Yergeau E. Harnessing phytomicrobiome signaling for rhizosphere microbiome engineering. Front Plant Sci. 2015;6:11. https://doi.org/10.3389/fpls.2015.00507.

32. Kumar A, Verma JP. Does plant-microbe interaction confer stress tolerance in plants: A review? Microbiol Res. 2018;207:41-52. https:// doi.org/10.1016/j.micres.2017.11.004.

33. Abbasi S, Spor A, Sadeghi A, Safaie N. Streptomyces strains modulate dynamics of soil bacterial communities and their efficacy in disease suppression caused by Phytophthora capsici. Sci Rep. 2021;11:9317. https://doi.org/10.1038/s41598-021-88495-y. 
34. Awla HK, Kadir J, Othman R, Rashid TS, Hamid S, Wong M-Y. Plant growth-promoting abilities and biocontrol efficacy of Streptomyces sp UPMRS4 against Pyricularia oryzae. Biol Control. 2017;112:55-63. https://doi.org/10.1016/j.biocontrol.2017.05.011.

35. Wu L, Xiao W, Chen G, Song D, Khaskheli MA, Li P, et al. Identification of Pseudomonas mosselii BS011 gene clusters required for suppression of rice blast fungus Magnaporthe oryzae. J Biotechnol. 2018;282:1-9. https://doi.org/10.1016/j.jbiotec.2018.04.016.

36. Fukamachi K, Konishi Y, Nomura T. Disease control of Phytophthora infestans using cyazofamid encapsulated in poly lactic-co-glycolic acid (PLGA) nanoparticles. Colloids Surf Physicochem Eng Aspects. 2019;577:315-22. https://doi.org/10.1016/j.colsurfa.2019.05.077.

37. Galsim F, Golabi MH, Kim YS, lyekar C. Comparative effects of composted organic waste and inorganic fertilizer on nitrate leachate from the farm soils of northern Guam. Int Soil Water Conserv Res. 2021;9(1):87-102. https://doi.org/10.1016/j.iswcr.2020.09.003.

38. Bouchet A-S, Laperche A, Bissuel-Belaygue C, Snowdon R, Nesi N, Stahl A. Nitrogen use efficiency in rapeseed. A review Agron Sustain Dev. 2016;36(2):38. https://doi.org/10.1007/s13593-016-0371-0.

39. Shah A, Nazari M, Antar M, Msimbira LA, Naamala J, Lyu D, et al. PGPR in agriculture: A sustainable approach to increasing climate change resilience. Front Sustain Food Syst. 2021;5: 667546. https://doi.org/10.3389/fsufs.2021.667546.

40. Lindemann SR. A piece of the pie: engineering microbiomes by exploiting division of labor in complex polysaccharide consumption. Curr Opin Chem Eng. 2020;30:96-102. https://doi.org/10.1016/j.coche.2020.08.004.

41. Mahmud K, Missaoui A, Lee K, Ghimire B, Presley HW, Makaju S. Rhizosphere microbiome manipulation for sustainable crop production. Curr Plant Biol. 2021;27: 100210. https://doi.org/10.1016/j.cpb.2021.100210.

42. Naamala J, Smith DL. Relevance of plant growth promoting microorganisms and their derived compounds, in the face of climate change. Agronomy. 2020;10(8):1179. https://doi.org/10.3390/agronomy10081179.

43. Turan M, Kıtır N, Alkaya Ü, Günes A, Tüfenkçi Ş, Yıldırım E, et al. Making Soil More Accessible to Plants: The Case of Plant Growth Promoting Rhizobacteria. In: Rigobelo EC, editor., et al., Plant Growth. New York: IntechOpen; 2016. p. 61-9.

44. Vessey JK. Plant growth promoting rhizobacteria as biofertilizers. Plant Soil. 2003;255(2):571-86. https://doi.org/10.1023/A:10260 37216893.

45. Yang WL, Gong T, Wang JW, Li GJ, Liu YY, Zhen J, et al. Effects of compound microbial fertilizer on soil characteristics and yield of wheat (Triticum aestivum L). Soil Sci Plant Nutr. 2020;20(4):2740-8. https://doi.org/10.1007/s42729-020-00340-9.

46. Erdemci l. Effects of seed microbial inoculant on growth, yield, and nutrition of durum wheat (Triticum durum L). Commun Soil Sci Plant Anal. 2021;52(7):792-801. https://doi.org/10.1080/00103624.2020.1869764.

47. Wang ZK, Chen ZY, Kowalchuk GA, Xu ZH, Fu XX, Kuramae EE. Succession of the resident soil microbial community in response to periodic inoculations. Appl Environ Microbiol. 2021;87(9):16. https://doi.org/10.1128/aem.00046-21.

48. Lau S-E, Hamdan MF, Pua T-L, Saidi NB, Tan BC. Plant nitric oxide signaling under drought stress. Plants. 2021;10(2):360. https://doi. org/10.3390/plants10020360.

49. Mohd Amnan MA, Pua T-L, Lau S-E, Tan BC, Yamaguchi H, Hitachi K, et al. Osmotic stress in banana is relieved by exogenous nitric oxide. PeerJ. 2021;9: e10879. https://doi.org/10.7717/peerj.10879.

50. Rodriguez R, Duran P. Natural holobiome engineering by using native extreme microbiome to counteract the climate change effects. Front Bioeng Biotechnol. 2020;8:14. https://doi.org/10.3389/fbioe.2020.00568.

51. Saikia J, Sarma RK, Dhandia R, Yadav A, Bharali R, Gupta VK, et al. Alleviation of drought stress in pulse crops with ACC deaminase producing rhizobacteria isolated from acidic soil of Northeast India. Sci Rep. 2018;8(1):3560. https://doi.org/10.1038/ s41598-018-21921-w.

52. Saleem AR, Brunetti C, Khalid A, Rocca G, Raio A, Emiliani G, et al. Drought response of Mucuna pruriens (L) DC inoculated with ACC deaminase and IAA producing rhizobacteria. PLoS ONE. 2018;13(2):e0191218. https://doi.org/10.1371/journal.pone.0191218.

53. Marasco R, Rolli E, Vigani G, Borin S, Sorlini C, Ouzari H, et al. Are drought-resistance promoting bacteria cross-compatible with different plant models? Plant Signal Behav. 2013;8(10): e26741. https://doi.org/10.4161/psb.26741.

54. Yoolong S, Kruasuwan W, Pham HTT, Jaemsaeng R, Jantasuriyarat C, Thamchaipenet A. Modulation of salt tolerance in Thai jasmine rice (Oryza sativa L cv KDML105) by Streptomyces venezuelae ATCC 10712 expressing ACC deaminase. Sci Rep. 2019;9(1):1275. https://doi. org/10.1038/s41598-018-37987-5.

55. Salwan R, Sharma A, Sharma V. Microbes mediated plant stress tolerance in saline agricultural ecosystem. Plant Soil. $2019 ; 442(1): 1-22$. https://doi.org/10.1007/s11104-019-04202-x.

56. Gou W, Tian L, Ruan Z, Zheng P, Chen F, Zhang L, et al. Accumulation of choline and glycinebetaine and drought stress tolerance induced in maize (Zea mays) by three plant growth promoting rhizobacteria (PGPR) strains. Pak J Bot. 2015;47(2):581-6.

57. Kanwal S, llyas N, Batool N, Arshad M. Amelioration of drought stress in wheat by combined application of PGPR, compost, and mineral fertilizer. J Plant Nutr. 2017;40(9):1250-60. https://doi.org/10.1080/01904167.2016.1263322.

58. Duran P, Tortella G, Sadowsky MJ, Viscardi S, Barra PJ, Mora MD. Engineering multigenerational host-modulated microbiota against soilborne pathogens in response to global climate change. Biology-Basel. 2021;10(9):21. https://doi.org/10.3390/biology10090865.

59. Saikia K, Bora LC, Bora P, Hazarika H. Management of bacterial blight in rice (Oryza sativa) through combined application of endophytes and rhizosphere antagonist. Indian J Agric Sci. 2020;90(12):2323-7.

60. Liu Y, Chen L, Wu G, Feng H, Zhang G, Shen Q, et al. Identification of root-secreted compounds involved in the communication between cucumber, the beneficial Bacillus amyloliquefaciens, and the soil-borne pathogen Fusarium oxysporum. Mol Plant-Microbe Interact. 2017;30(1):53-62. https://doi.org/10.1094/mpmi-07-16-0131-r.

61. Xu X, Fang P, Zhang H, Chi C, Song L, Xia X, et al. Strigolactones positively regulate defense against root-knot nematodes in tomato. J Exp Bot. 2018;70(4):1325-37. https://doi.org/10.1093/jxb/ery439.

62. Zhao D, Zhao H, Zhao D, Zhu X, Wang Y, Duan Y, et al. Isolation and identification of bacteria from rhizosphere soil and their effect on plant growth promotion and root-knot nematode disease. Biol Control. 2018;119:12-9. https://doi.org/10.1016/j.biocontrol.2018.01. 004.

63. De Vrieze M, Germanier F, Vuille N, Weisskopf L. Combining different potato-associated Pseudomonas strains for improved biocontrol of Phytophthora infestans. Front Microbiol. 2018;9:2573. https://doi.org/10.3389/fmicb.2018.02573.

64. Santhanam R, Luu VT, Weinhold A, Goldberg J, Oh Y, Baldwin IT. Native root-associated bacteria rescue a plant from a sudden-wilt disease that emerged during continuous cropping. Proc Natl Acad Sci USA. 2015;112(36):E5013-20. https://doi.org/10.1073/pnas.1505765112. 
65. López-Ráez JA, Shirasu K, Foo E. Strigolactones in plant interactions with beneficial and detrimental organisms: The yin and yang. Trends Plant Sci. 2017;22(6):527-37. https://doi.org/10.1016/j.tplants.2017.03.011.

66. Qiu ZG, Egidi E, Liu HW, Kaur S, Singh BK. New frontiers in agriculture productivity: Optimised microbial inoculants and in situ microbiome engineering. Biotechnol Adv. 2019;37(6):11. https://doi.org/10.1016/j.biotechadv.2019.03.010.

67. Uroz S, Courty PE, Oger P. Plant symbionts are engineers of the plant-associated microbiome. Trends Plant Sci. 2019;24(10):905-16. https://doi.org/10.1016/j.tplants.2019.06.008.

68. Foo JL, Ling H, Lee YS, Chang MW. Microbiome engineering: current applications and its future. Biotechnol J. 2017;12(3):9. https://doi. org/10.1002/biot.201600099.

69. Bodor A, Bounedjoum N, Vincze GE, Erdeiné Kis Á, Laczi K, Bende G, et al. Challenges of unculturable bacteria: Environmental perspectives. Rev Environ Sci Biotechnol. 2020;19(1):1-22. https://doi.org/10.1007/s11157-020-09522-4.

70. Ke J, Wang B, Yoshikuni Y. Microbiome engineering: Synthetic biology of plant-associated microbiomes in sustainable agriculture. Trends Biotechnol. 2021;39(3):244-61. https://doi.org/10.1016/j.tibtech.2020.07.008.

71. Bulgari R, Franzoni G, Ferrante A. Biostimulants application in horticultural crops under abiotic stress conditions. Agronomy. $2019 ; 9(6): 306$. https://doi.org/10.3390/agronomy9060306.

72. Baltazar M, Correia S, Guinan KJ, Sujeeth N, Bragança R, Gonçalves B. Recent advances in the molecular effects of biostimulants in plants: an overview. Biomolecules. 2021;11(8):1096. https://doi.org/10.3390/biom11081096.

73. Sangiorgio D, Cellini A, Donati I, Pastore C, Onofrietti C, Spinelli F. Facing climate change: Application of microbial biostimulants to mitigate stress in horticultural crops. Agronomy. 2020;10(6):794. https://doi.org/10.3390/agronomy10060794.

74. Sible CN, Seebauer JR, Below FE. Plant biostimulants: A categorical review, their implications for row crop production, and relation to soil health indicators. Agronomy. 2021;11(7):1297. https://doi.org/10.3390/agronomy11071297.

75. Castiglione AM, Mannino G, Contartese V, Bertea CM, Ertani A. Microbial biostimulants as response to modern agriculture needs: Composition, role and application of these innovative products. Plants. 2021;10(8):1533. https://doi.org/10.3390/plants10081533.

76. Del Buono D. Can biostimulants be used to mitigate the effect of anthropogenic climate change on agriculture? It is time to respond. Sci Total Environ. 2021;751:141763. https://doi.org/10.1016/j.scitotenv.2020.141763.

77. Zhang X, Schmidt R. The impact of growth regulators on alpha-tocopherol status of water-stressed Poa pratensis L. Int Turfgrass Soc Res J. 1997;8:1364-2137.

78. European Parliament and European Council. Regulation (EU) 2019/1009 of the European Parliament and of the Council of 5 June 2019 laying down rules on the making available on the market of EU fertilising products and amending Regulations (EC) No 1069/2009 and (EC) No 1107/2009 and repealing Regulation (EC) No 2003/2003. Off J Eur Union. 2019; L 170 (62):1-114.

79. European Parliament and European Council. Commission Implementing Regulation (EU) No 354/2014 of 8 April 2014 amending and correcting Regulation (EC) No 889/2008 laying down detailed rules for the implementation of Council Regulation (EC) No $834 / 2007$ on organic production and labelling of organic products with regard to organic production, labelling and control. Off J Eur Union. 2014;106 (57):7-14.

80. Caradonia F, Battaglia V, Righi L, Pascali G, La Torre A. Plant biostimulant regulatory framework: Prospects in Europe and current situation at international level. J Plant Growth Regul. 2019;38(2):438-48. https://doi.org/10.1007/s00344-018-9853-4.

81. Bulgari R, Cocetta G, Trivellini A, Vernieri P, Ferrante A. Biostimulants and crop responses: A review. Biol Agric Hortic. $2015 ; 31$ (1):1-17. https://doi.org/10.1080/01448765.2014.964649.

82. du Jardin P. Plant biostimulants: Definition, concept, main categories and regulation. Sci Hortic. 2015;196:3-14. https://doi.org/10.1016/j. scienta.2015.09.021.

83. Basak A. Biostimulators-definitions, classification and legislation. In: Gawrońska H, editor. Monographs Series: Biostimulators in Modern Agriculture. General Aspects. Warsaw: Wieś Jutra; 2008. p. 7-17.

84. Lugtenberg B, Kamilova F. Plant-growth-promoting rhizobacteria. Annu Rev Microbiol. 2009;63:541-56. https://doi.org/10.1146/annur ev.micro.62.081307.162918.

85. Dodd IC, Ruiz-Lozano JM. Microbial enhancement of crop resource use efficiency. Curr Opin Biotechnol. 2012;23(2):236-42. https://doi. org/10.1016/j.copbio.2011.09.005.

86. Philippot L, Raaijmakers JM, Lemanceau P, Van Der Putten WH. Going back to the roots: The microbial ecology of the rhizosphere. Nat Rev Microbiol. 2013;11(11):789-99. https://doi.org/10.1038/nrmicro3109.

87. Spatafora JW, Chang Y, Benny GL, Lazarus K, Smith ME, Berbee ML, et al. A phylum-level phylogenetic classification of zygomycete fungi based on genome-scale data. Mycologia. 2016;108(5):1028-46. https://doi.org/10.3852/16-042.

88. Giovannini L, Palla M, Agnolucci M, Avio L, Sbrana C, Turrini A, et al. Arbuscular mycorrhizal fungi and associated microbiota as plant biostimulants: Research strategies for the selection of the best performing inocula. Agronomy. 2020;10:21. https://doi.org/10.3390/ agronomy10010108.

89. Eef B, Marlies D, Van Swam K, Veen A, Burger L. Identification of the seaweed biostimulant market (Phase1). The Hague: North Sea Farm Foundation; 2018.

90. El Boukhari MELM, Barakate M, Bouhia Y, Lyamlouli K. Trends in seaweed extract based biostimulants: manufacturing process and beneficial effect on soil-plant systems. Plants. 2020;9(3):359. https://doi.org/10.3390/plants9030359.

91. Newton L. Seaweed utilization. Nature. 1951;167(4260):1004. https://doi.org/10.1038/1671004a0.

92. Khan W, Rayirath UP, Subramanian S, Jithesh MN, Rayorath P, Hodges DM, et al. Seaweed extracts as biostimulants of plant growth and development. J Plant Growth Regul. 2009;28(4):386-99. https://doi.org/10.1007/s00344-009-9103-x.

93. Hernández-Herrera RM, Santacruz-Ruvalcaba F, Ruiz-López MA, Norrie J, Hernández-Carmona G. Effect of liquid seaweed extracts on growth of tomato seedlings (Solanum lycopersicum L.). J Appl Phycol. 2014;26(1):619-28. https://doi.org/10.1007/s10811-013-0078-4.

94. Kapoore RV, Wood EE, Llewellyn CA. Algae biostimulants: A critical look at microalgal biostimulants for sustainable agricultural practices. Biotechnol Adv. 2021;49:107754. https://doi.org/10.1016/j.biotechadv.2021.107754.

95. Jindo K, Canellas LP, Albacete A, Santos L, Rocha RL, Carvalho Baia D, et al. Interaction between humic substances and plant hormones for phosphorous acquisition. Agronomy. 2020;10(5):640. 
96. Rouphael Y, Colla G. Synergistic biostimulatory action: Designing the next generation of plant biostimulants for sustainable agriculture. Front Plant Sci. 2018;9:1655. https://doi.org/10.3389/fpls.2018.01655.

97. Malik A, Mor VS, Tokas J, Punia H, Malik S, Malik K, et al. Biostimulant-treated seedlings under sustainable agriculture: a global perspective facing climate change. Agronomy-Basel. 2021;11(1):24. https://doi.org/10.3390/agronomy11010014.

98. Drobek M, Frąc M, Cybulska J. Plant biostimulants: Importance of the quality and yield of horticultural crops and the improvement of plant tolerance to abiotic stress—a review. Agronomy. 2019;9(6):335. https://doi.org/10.3390/agronomy9060335.

99. Hassan SM, Ashour M, Sakai N, Zhang L, Hassanien HA, Gaber A, et al. Impact of seaweed liquid extract biostimulant on growth, yield, and chemical composition of cucumber (Cucumis sativus). Agriculture (Switzerland). 2021;11(4):320. https://doi.org/10.3390/agricultur e11040320.

100. Chandra D, Srivastava R, Glick BR, Sharma AK. Drought-tolerant Pseudomonas spp. improve the growth performance of finger millet (Eleusine coracana (L.) Gaertn.) under non-stressed and drought-stressed conditions. Pedosphere. 2018;28(2):227-40. https://doi.org/ 10.1016/S1002-0160(18)60013-X.

101. Ekin Z. Integrated use of humic acid and plant growth promoting rhizobacteria to ensure higher potato productivity in sustainable agriculture. Sustainability. 2019;11:12. https://doi.org/10.3390/su10023417.

102. Stanley-Raja V, Senthil-Nathan S, Chanthini KMP, Sivanesh H, Ramasubramanian R, Karthi S, et al. Biological activity of chitosan inducing resistance efficiency of rice (Oryza sativa $L$ ) after treatment with fungal based chitosan. Sci Rep. 2021;11(1):1-15. https://doi.org/10.1038/ s41598-021-99391-w.

103. Kundu A, Raha P, Dubey AN, Rani M, Paul A, Patel R. Differential responses of rice (Oryza sativa L.) to foliar fertilization of organic potassium salts. J Plant Nutr. 2021;44(9):1330-48. https://doi.org/10.1080/01904167.2020.1862193.

104. Kulkarni MG, Rengasamy KRR, Pendota SC, Gruz J, Plačková L, Novák O, et al. Bioactive molecules derived from smoke and seaweed Ecklonia maxima showing phytohormone-like activity in Spinacia oleracea L. N Biotechnol. 2018;2019(48):83-9. https://doi.org/10. 1016/j.nbt.2018.08.004.

105. Hayat S, Ahmad H, Ali M, Ren K, Cheng Z. Aqueous garlic extract stimulates growth and antioxidant enzymes activity of tomato (Solanum lycopersicum). Sci Hortic. 2016;2018(240):139-46. https://doi.org/10.1016/j.scienta.2018.06.011.

106. Duc NH, Csintalan Z, Posta K. Arbuscular mycorrhizal fungi mitigate negative effects of combined drought and heat stress on tomato plants. Plant Physiol Biochem. 2018;132:297-307. https://doi.org/10.1016/j.plaphy.2018.09.011.

107. Ansari FA, Ahmad I, Pichtel J. Growth stimulation and alleviation of salinity stress to wheat by the biofilm forming Bacillus pumilus strain FAB10. Appl Soil Ecol. 2019;143:45-54. https://doi.org/10.1016/j.apsoil.2019.05.023.

108. Yasmin H, Nosheen A, Naz R, Bano A, Keyani R. L-tryptophan-assisted PGPR-mediated induction of drought tolerance in maize (Zea mays L). J Plant Interact. 2017;12(1):567-78. https://doi.org/10.1080/17429145.2017.1402212.

109. AbdelMegeed TM, Gharib HS, Hafez EM, El-Sayed A. Effect of some plant growth regulators and biostimulants on the productivity of Sakha108 rice plant (Oryza sativa L.) under different water stress conditions. Appl Ecol Environ Res. 2021;19(4):2859-78.

110. Francesca S, Cirillo V, Raimondi G, Maggio A, Barone A, Rigano MM. A novel protein hydrolysate-based biostimulant improves tomato performances under drought stress. Plants. 2021. https://doi.org/10.3390/plants10040783.

111. Quintero-Calderón EH, Sánchez-Reinoso AD, Chávez-Arias CC, Garces-Varon G, Restrepo-Díaz H. Rice seedlings showed a higher heat tolerance through the foliar application of biostimulants. Notulae Botanicae Horti Agrobotanici Cluj-Napoca. 2021;49:1. https://doi. org/10.15835/nbha49112120.

112. Niu C, Wang G, Sui J, Liu G, Ma F, Bao Z. Biostimulants alleviate temperature stress in tomato seedlings. Sci Hortic. 2021;2022(293): 110712. https://doi.org/10.1016/j.scienta.2021.110712.

113. Carmody N, Goñi O, Łangowski $Ł$, Connell S. Ascophyllum nodosum extract biostimulant processing and its impact on enhancing heat stress tolerance during tomato fruit set. Front Plant Sci. 2020;11:807. https://doi.org/10.3389/fpls.2020.00807.

114. Hashem A, Alqarawi AA, Radhakrishnan R, Al-Arjani ABF, Aldehaish HA, Egamberdieva D, et al. Arbuscular mycorrhizal fungi regulate the oxidative system, hormones and ionic equilibrium to trigger salt stress tolerance in Cucumis sativus L. Saudi J Biol Sci. 2018;25(6):1102-14. https://doi.org/10.1016/j.sjbs.2018.03.009.

115. Souza AC, Zandonadi DB, Santos MP, Canellas NOA, de Paula SC, da Silva Irineu LES, et al. Acclimation with humic acids enhances maize and tomato tolerance to salinity. Chem Biol Technol Agric. 2021;8(1):1-13. https://doi.org/10.1186/s40538-021-00239-2.

116. Khan MS, Pandey MK, Hemalatha S. Comparative studies on the role of organic biostimulant in resistant and susceptible cultivars of rice grown under saline stress - organic biostimulant alleviate saline stress in tolerant and susceptible cultivars of rice. J Crop Sci Biotechnol. 2018;21(5):459-67. https://doi.org/10.1007/s12892-018-0089-0.

117. Nawaz A, Shahbaz M, Asadullah M, Imran A, Marghoob MU, Imtiaz M, et al. Potential of salt tolerant PGPR in growth and yield augmentation of wheat (Triticum aestivum L) under saline conditions. Front Microbiol. 2020;11:2019. https://doi.org/10.3389/fmicb. 2020.02019.

118. Lira AC, Mascarin GM, Delalibera Júnior Í. Microsclerotia production of Metarhizium spp. for dual role as plant biostimulant and control of Spodoptera frugiperda through corn seed coating. Fungal Biol. 2020;124(8):689-99. https://doi.org/10.1016/j.funbio.2020.03.011.

119. Sahana BN, PrasannaKumar MK, Mahesh HB, Buela Parivallal P, Puneeth ME, Gautam C, et al. Biostimulants derived from red seaweed stimulate the plant defence mechanism in rice against Magnaporthe oryzae. J Appl Phycol. 2021. https://doi.org/10.1007/s10811-021-02627-5.

120. Dey P, Ramanujam R, Venkatesan G, Nagarathnam R. Sodium alginate potentiates antioxidant defense and PR proteins against early blight disease caused by Alternaria solani in Solanum lycopersicum Linn. PLoS ONE. 2019;14(9):1-26. https://doi.org/10.1371/journal. pone.0223216.

121. Dhouib H, Zouari I, Ben Abdallah D, Belbahri L, Taktak W, Triki MA, et al. Potential of a novel endophytic Bacillus velezensis in tomato growth promotion and protection against Verticillium wilt disease. Biol Control. 2019;139:104092. https://doi.org/10.1016/j.biocontrol. 2019.104092.

122. da Silva APS, Olivares FL, Sudré CP, Peres LEP, Canellas NA, da Silva RM, et al. Attenuations of bacterial spot disease Xanthomonas euvesicatoria on tomato plants treated with biostimulants. Chem Biol Technol Agric. 2021;8(1):42. https://doi.org/10.1186/s40538-021-00240-9. 
123. Le Mire G, Siah A, Marolleau B, Gaucher M, Maumené C, Brostaux Y, et al. Evaluation of I-carrageenan, CpG-ODN, glycine betaine, Spirulina platensis, and ergosterol as elicitors for control of Zymoseptoria tritici in wheat. Phytopathology. 2019;109(3):409-17. https://doi.org/10. 1094/PHYTO-11-17-0367-R.

124. Gunupuru LR, Patel JS, Sumarah MW, Renaud JB, Mantin EG, Prithiviraj B. A plant biostimulant made from the marine brown algae Ascophyllum nodosum and chitosan reduce Fusarium head blight and mycotoxin contamination in wheat. PLoS ONE. 2019;14(9): e0220562. https://doi.org/10.1371/journal.pone.0220562.

125. Ertani A, Francioso O, Tinti A, Schiavon M, Pizzeghello D, Nardi S. Evaluation of seaweed extracts from laminaria and Ascophyllum nodosum spp as biostimulants in Zea mays L using a combination of chemical, biochemical and morphological approaches. Front Plant Sci. 2018;9:428. https://doi.org/10.3389/fpls.2018.00428.

126. Billard V, Etienne P, Jannin L, Garnica M, Cruz F, Garcia-Mina J-M, et al. Two biostimulants derived from algae or humic acid induce similar responses in the mineral content and gene expression of winter oilseed rape (Brassica napus L). J Plant Growth Regul. 2014;33(2):305-16. https://doi.org/10.1007/s00344-013-9372-2.

127. Fan D, Hodges DM, Critchley AT, Prithiviraj B. A commercial extract of brown macroalga (Ascophyllum nodosum) affects yield and the nutritional quality of spinach in vitro. Commun Soil Sci Plant Anal. 2013;44(12):1873-84. https://doi.org/10.1080/00103624.2013.790404.

128. Chitarra W, Pagliarani C, Maserti B, Lumini E, Siciliano I, Cascone P, et al. Insights on the impact of arbuscular mycorrhizal symbiosis on tomato tolerance to water stress. Plant Physiol. 2016;171(2):1009-23. https://doi.org/10.1104/pp.16.00307.

129. Rouphael Y, Colla G. Editorial: Biostimulants in agriculture. Front Plant Sci. 2020;11:40. https://doi.org/10.3389/fpls.2020.00040.

130. González-Morales S, Solís-Gaona S, Valdés-Caballero MV, Juárez-Maldonado A, Loredo-Treviño A, Benavides-Mendoza A. Transcriptomics of biostimulation of plants under abiotic stress. Front Genet. 2021;12:36. https://doi.org/10.3389/fgene.2021.583888.

131. Moolphuerk N, Lawson T, Pattanagul W. Chitosan mitigates the adverse effects and improves photosynthetic activity in rice (Oryza sativa L) seedlings under drought condition. J Crop Improv. 2021. https://doi.org/10.1080/15427528.2021.2000544.

132. Pačuta V, Rašovský M, Michalska-Klimczak B, Wyszyňski Z. Grain yield and quality traits of durum wheat (Triticum durum Desf) treated with seaweed-and humic acid-based biostimulants. Agronomy. 2021;11(7):1270. https://doi.org/10.3390/agronomy11071270.

133. Mannino G, Nerva L, Gritli T, Novero M, Fiorilli V, Bacem M, et al. Effects of different microbial inocula on tomato tolerance to water deficit. Agronomy. 2020;10(2):170. https://doi.org/10.3390/agronomy10020170.

134. Li H, Yue H, Li L, Liu Y, Zhang H, Wang J, et al. Seed biostimulant Bacillus sp MGW9 improves the salt tolerance of maize during seed germination. AMB Express. 2021;11(1):74. https://doi.org/10.1186/s13568-021-01237-1.

135. Zou P, Lu X, Zhao H, Yuan Y, Meng L, Zhang C, et al. Polysaccharides derived from the brown algae Lessonia nigrescens enhance salt stress tolerance to wheat seedlings by enhancing the antioxidant system and modulating intracellular ion concentration. Front Plant Sci. 2019;10:48. https://doi.org/10.3389/fpls.2019.00048.

136. Rehman HU, Alharby HF, Bamagoos AA, Abdelhamid MT, Rady MM. Sequenced application of glutathione as an antioxidant with an organic biostimulant improves physiological and metabolic adaptation to salinity in wheat. Plant Physiol Biochem. 2021;158:43-52. https://doi.org/10.1016/j.plaphy.2020.11.041.

137. Tigka T, Ipsilantis I. Effects of sand dune, desert and field arbuscular mycorrhizae on lettuce (Lactuca sativa, L) growth in a natural saline soil. Sci Hortic. 2020;264:109191. https://doi.org/10.1016/j.scienta.2020.109191.

138. Gimenez E, Salinas M, Manzano-Agugliaro F. Worldwide research on plant defense against biotic stresses as improvement for sustainable agriculture. Sustainability. 2018;10(2):391.

139. Sangha JS, Kandasamy S, Khan W, Bahia NS, Singh RP, Critchley AT, et al. $\lambda$-carrageenan suppresses tomato chlorotic dwarf viroid (TCDVd) replication and symptom expression in tomatoes. Mar Drugs. 2015;13(5):2875-89. https://doi.org/10.3390/md13052875.

140. de Oliveira Filho JG, Rodrigues JM, Valadares ACF, de Almeida AB, Valencia-Mejia E, Fernandes KF, et al. Bioactive properties of protein hydrolysate of cottonseed byproduct: Antioxidant, antimicrobial, and angiotensin-converting enzyme (ACE) inhibitory activities. Waste Biomass Valorization. 2021;12(3):1395-404. https://doi.org/10.1007/s12649-020-01066-6.

141. Kumaraswamy RV, Kumari S, Choudhary RC, Sharma SS, Pal A, Raliya R, et al. Salicylic acid functionalized chitosan nanoparticle: a sustainable biostimulant for plant. Int J Biol Macromol. 2019;123:59-69. https://doi.org/10.1016/j.ijbiomac.2018.10.202.

142. Rudrappa T, Biedrzycki ML, Kunjeti SG, Donofrio NM, Czymmek KJ, Paul WP, et al. The rhizobacterial elicitor acetoin induces systemic resistance in Arabidopsis thaliana. Commun Integr Biol. 2010;3(2):130-8. https://doi.org/10.4161/cib.3.2.10584.

143. Príncipe A, Fernandez M, Torasso M, Godino A, Fischer S. Effectiveness of tailocins produced by Pseudomonas fluorescens SF4c in controlling the bacterial-spot disease in tomatoes caused by Xanthomonas vesicatoria. Microbiol Res. 2018;212-213:94-102. https://doi.org/ 10.1016/j.micres.2018.05.010.

144. Divya K, Vijayan S, George TK, Jisha MS. Antimicrobial properties of chitosan nanoparticles: mode of action and factors affecting activity. Fibers Polym. 2017;18(2):221-30. https://doi.org/10.1007/s12221-017-6690-1.

145. Liu H, Du Y, Wang X, Sun L. Chitosan kills bacteria through cell membrane damage. Int J Food Microbiol. 2004;95(2):147-55. https://doi. org/10.1016/j.ijfoodmicro.2004.01.022.

146. Siriwong S, Thepbandit W, Hoang NH, Papathoti NK, Teeranitayatarn K, Saardngen T, et al. Identification of a chitooligosaccharide mechanism against bacterial leaf blight on rice by in vitro and in silico studies. Int J Mol Sci. 2021;22(15):7990.

147. Markets and Markets. Biostimulants Market by Active Ingredients (Humic Substances, Seaweed Extracts, Microbial Amendments, Amino Acids), Mode of Application (Folier, Soil Treatment, Seed Treatment), Form (Liquid, and Dry), Crop Type, \& by Region - Global Forecast to 2026. 2021. p. 337.

148. Behera B, Venkata Supraja K, Paramasivan B. Integrated microalgal biorefinery for the production and application of biostimulants in circular bioeconomy. Bioresour Technol. 2021;339: 125588. https://doi.org/10.1016/j.biortech.2021.125588.

149. van Eck NJ, Waltman L. Software survey: VOSviewer, a computer program for bibliometric mapping. Scientometrics. 2010;84(2):523-38. https://doi.org/10.1007/s11192-009-0146-3.

150. Yakhin OI, Lubyanov AA, Yakhin IA, Brown PH. Biostimulants in plant science: A global perspective. Front Plant Sci. 2017;7:2049. https:// doi.org/10.3389/fpls.2016.02049.

Publisher's Note Springer Nature remains neutral with regard to jurisdictional claims in published maps and institutional affiliations. 